\title{
Effects of crystallographic anisotropy on fracture development and acoustic emission in quartz
}

\author{
Nick E. Timms, ${ }^{1}$ David Healy, ${ }^{1,2}$ Juan M. Reyes-Montes, ${ }^{3}$ David S. Collins, ${ }^{4,5}$ \\ Dave J. Prior, ${ }^{6}$ and R. Paul Young ${ }^{4}$ \\ Received 7 July 2009; revised 6 January 2010; accepted 25 February 2010; published 10 July 2010.
}

[1] Transgranular microcracking is fundamental for the initiation and propagation of all fractures in rocks. The geometry of these microcracks is primarily controlled by the interaction of the imposed stress field with the mineral elastic properties. However, the effects of anisotropic elastic properties of minerals on brittle fracture are not well understood. This study examines the effects of elastic anisotropy of quartz on the geometry of brittle fracture and related acoustic emissions (AE) developed during indentation experiments on single crystals at ambient pressure and temperature. A Hertzian cone crack developed during blunt indentation of a single crystal of flawless Brazilian quartz parallel to the $c$ axis shows geometric deviation away from predictions based on the isotropic case, consistent with trigonal symmetry. The visible cone crack penetration depth varies from 3 to $5 \mathrm{~mm}$ and apical angle from $53^{\circ}$ to $40^{\circ}$. Electron backscatter diffraction (EBSD) mapping of the crack tip shows that fracturing initiates along a $\sim 40 \mu \mathrm{m}$ wide process zone, comprising damage along overlapping en echelon high-index crystallographic planes, shown by discrete bands of reduced electron backscatter pattern (EBSP) quality (band contrast). Coalescence of these surfaces results in a stepped fracture morphology. Monitoring of AE during indentation reveals that the elastic anisotropy of quartz has a significant effect on AE location and focal mechanisms. Ninety-four AE events were recorded during indentation and show an increasing frequency with increasing load. They correspond to the development of subsidiary concentric cracks peripheral to the main cone crack. The strong and complex anisotropy in seismic velocity $\left(\sim 28 \% \mathrm{~V}_{\mathrm{p}}, \sim 43 \% \mathrm{~V}_{\mathrm{s}}\right.$ with trigonal symmetry) resulted in inaccurate and high uncertainty in AE locations using Geiger location routine with an isotropic velocity model. This problem was overcome by using a relative (master event) location algorithm that only requires a priori knowledge of the velocity structure within the source volume. The AE location results correlate reasonably well to the extent of the observed cone crack. Decomposition of AE source mechanisms of the Geiger relocated events shows dominantly end-member behavior between tensile and compressive vector dipole events, with some double-coupledominated events and no purely tensile or compressive events. The same events located by the master event algorithm yield greater percentage of vector dipole components and no double-couple events, indicating that AE source mechanism solutions can depend on AE location accuracy, and therefore, relocation routine that is utilized. Calculations show that the crystallographic anisotropy of quartz causes apparent deviation of the moment tensors away from double-couple and pure tensile/compressive sources consistent with the observations. Preliminary modeling of calcite anisotropy shows a response distinct from quartz, indicating that the effects of anisotropy on interpreting AE are complex and require detailed further study.

Citation: Timms, N. E., D. Healy, J. M. Reyes-Montes, D. S. Collins, D. J. Prior, and R. P. Young (2010), Effects of crystallographic anisotropy on fracture development and acoustic emission in quartz, J. Geophys. Res., 115, B07202, doi:10.1029/2009JB006765.

\footnotetext{
${ }^{1}$ Department of Applied Geology, Western Australia Geothermal Centre of Excellence, Curtin University of Technology, Perth, Western Australia, Australia.

Copyright 2010 by the American Geophysical Union. 0148-0227/10/2009JB006765
}

\footnotetext{
${ }^{2}$ Now at School of Geosciences, King's College, University of Aberdeen, Aberdeen, UK.

${ }^{3}$ Applied Seismology Consultants, Shrewsbury, UK

${ }^{4}$ University of Toronto, Toronto, Ontario, Canada.

${ }^{5}$ Now at Engineering Seismology Group, Kingston, Ontario, Canada.

${ }^{6}$ Department of Earth and Ocean Sciences, University of Liverpool, Liverpool, UK.
} 


\section{Introduction}

[2] Brittle failure of a rock is achieved by microcracking at the grain scale [Hallbauer et al., 1973; Kranz, 1983; Lockner et al., 1992; Tapponnier and Brace, 1976; Wong, 1982], and the geometry and orientation of these microcracks have been shown to influence their subsequent interaction and coalescence as they form macroscopic failure planes, such as faults or joints [Healy et al., 2006; Reches and Lockner, 1994]. The orientation, density, and connectivity of microcracks exert a significant influence on many bulk physical properties of rocks, including permeability, elastic anisotropy, and rheology, and therefore microcracks have fundamentally important implications for fluid flow (groundwater, geothermal, hydrothermal, hydrocarbons), seismic anisotropy, earthquakes, and rock strength evolution. Studies that have attempted to quantify fault-related damage by measuring grain-scale fractures have so far been restricted to data from quartz grains, even in polymineralic rocks [Anders and Wiltschko, 1994; Mitchell and Faulkner, 2009; Vermilye and Scholz, 1998a; Wilson et al., 2003]. Interpretation of these fractures and their influence is inherently limited by widely held assumptions (1) that quartz is "effectively" or "nearly" elastically isotropic and (2) that the grain-scale fractures are planar. In reality however, quartz exhibits significant elastic anisotropy (Figure 1), and there are many observations of nonplanar fractures in deformed rocks [e.g., Hallbauer et al., 1973; Kranz, 1983; Moore and Lockner, 1995; Tapponnier and Brace, 1976; Wong, 1982].

[3] Grain-scale processes exert a fundamental control on the initiation and propagation of all fractures. For a given applied stress field, the nucleation/initiation of fractures in crystalline rocks depends on the interaction between the imposed stress field, the elastic properties of the constituent minerals, and the nature of the intergrain contacts [e.g., Hallbauer et al., 1973; Tapponnier and Brace, 1976]. Essentially, failure can occur in two ways: (1) along the grain interfaces ("intergranular") and (2) across intact grains ("intragranular" or "transgranular"). The formation of an intragranular or transgranular crack is a function of the interaction of the local grain-scale stress field with the elastic properties of the mineral forming the grain. Impinging grain-grain contacts are sites of transgranular crack nucleation [McEwen, 1981], because they can locally modify the orientation and magnitude of the principal stresses and provide contrasts in magnitude or orientation of mechanical (e.g., elastic) properties. Our understanding of fracture mechanics in rocks is well developed for the isotropic case. For example, the stress distribution around impinging grain contacts is similar to that of a blunt indenter described by Hertz [1896]. For isotropic materials, Hertzian loading initiates surface ring cracks outside the indenter contact area that grow outward and downward into a rotationally symmetrical cone crack of predictable geometry [Hertz, 1896; Kocer and Collins, 1998; Lawn, 1998; Swain et al., 1973; Yingzhi and Hills, 1991]. However, most important rock-forming minerals have anisotropic material properties, and the theories that underpin our understanding of brittle failure in rocks have yet to incorporate this key fact.
[4] Prior to the development of a mechanical theory for anisotropic rocks, it is essential to understand the effects of mineral anisotropy on brittle fracture. The symmetry and strength of the elastic anisotropy in a given mineral is largely controlled by its crystallographic structure (Figure 1). This elastic anisotropy gives rise to two key phenomena: (1) directional variations in resistance to fracture, i.e., fracture toughness anisotropy, or $\mathrm{AK}_{\mathrm{Ic}}$, and (2) anisotropy of seismic wave velocities, $\mathrm{AV}_{\mathrm{p}}$ and $\mathrm{AV}_{\mathrm{s}}[$ Babuška and Cara, 1991] (Figure 1). The effects of elastic anisotropy on fracture toughness are not well documented for minerals without prominent cleavage such as quartz, and published data for the anisotropy of fracture toughness of different minerals at various conditions remain sparse. Values of $\mathrm{K}_{\mathrm{Ic}}$ for different crystallographic directions in quartz vary from $1.74 \mathrm{MN} \mathrm{m}^{-3 / 2}$ parallel to $r\{10-10\}$ to $2.40 \mathrm{MN} \mathrm{m}^{-3 / 2}$ parallel to $c\{0001\}$ [Atkinson, 1982; Atkinson and Avdis, 1980; Ferguson et al., 1987; Hartley and Wilshaw, 1973; Norton and Atkinson, 1981], although these variations may partly reflect the differences between experimental techniques [e.g., Ferguson et al., 1987]. Hartley and Wilshaw [1973] produced crsytallographically controlled cone cracks during ball indentation experiments on synthetic quartz. They observed that the symmetry of the crystal structure influenced the shape of the cone cracks, with eccentric surface ring cracks with symmetric cusps developed in the $\langle a\rangle$ directions, similarly symmetric tricuspate cone cracks, and generation of Dauphiné twins. Ball and Payne [1976] demonstrated that quartz shows preference for fracture along the rhombohedral planes. However, the precise nature of the effects of $\mathrm{AK}_{\mathrm{Ic}}$ on fracture geometry remains to be tested.

[5] The effect of bulk rock elastic properties that arise from the crystallographic preferred orientation of mineral grains on seismic velocity anisotropy has long been established [Blackman et al., 2002; Healy et al., 2009; Hess, 1964; Lloyd and Kendall, 2005; Mainprice and Silver, 1993; Tatham et al., 2008]. However, the effects of elastic anisotropy on the location and source mechanisms of acoustic emissions (AE) and earthquakes generated by the release of elastic energy during brittle fracture are still an emerging field. AE monitoring has become a routine tool in the monitoring of brittle deformation experiments [e.g., de Ronde et al., 2007; Lockner et al., 1992; Pettitt and King, 2004; Scholz, 1968], providing a unique insight into the evolution of the fracture localization and geometry. Firstorder information on the fracturing process at any scale is provided by the location of recorded seismic events. Typically, a source location is obtained by minimizing residuals between the arrival times recorded at each of the monitoring instruments and the theoretical travel times computed assuming a velocity model for the study volume. The accuracy of the location therefore depends on the monitoring array geometry, the precision in determining the arrival times, and the accuracy of the chosen velocity model [Pavlis, 1986]. Recent advances in the location of regional scale earthquakes have successfully reduced hypocentral uncertainties by an order of magnitude by using relative location methods that reduce the location volume to a small region around the seismic source. These methods are valid provided that the separation between hypocenters of the processed events is small compared with the array dimen- 
A Quartz

Crystallography

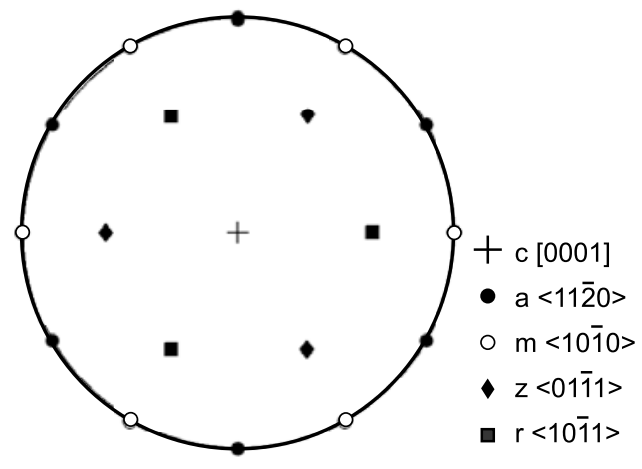

Anisotropy of $E 60.83 \%$

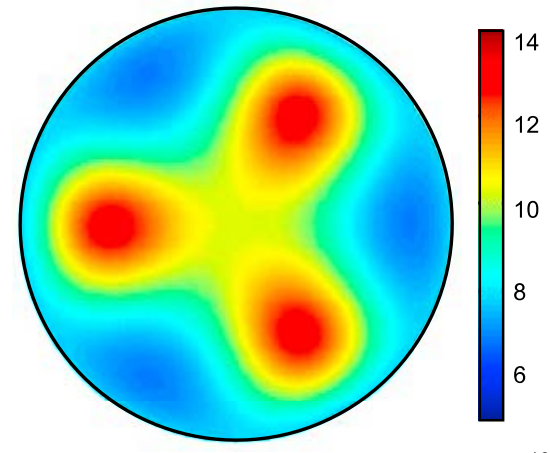

$\operatorname{Pa} \times 10^{10}$

$\mathrm{AV}_{\mathrm{p}} 27.59 \%$

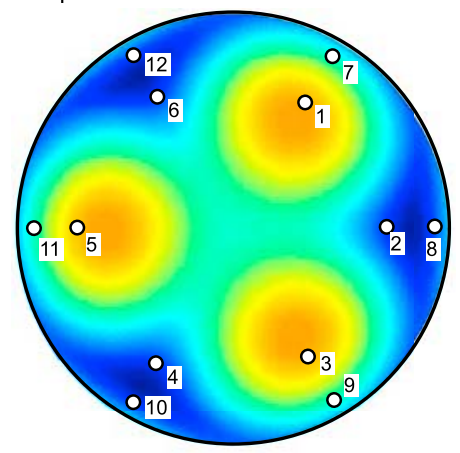

0 pinducer focal coverage

$\mathrm{AV}_{\mathrm{s}} 42.65 \%$

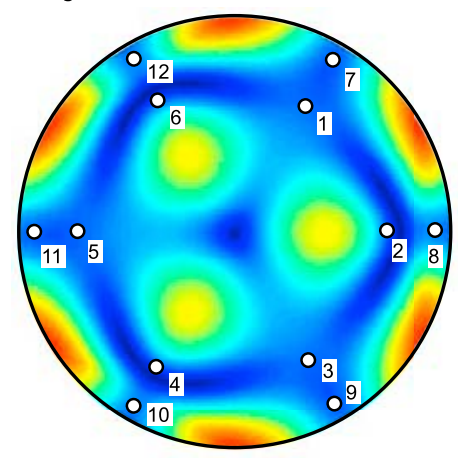

○ pinducer focal coverage

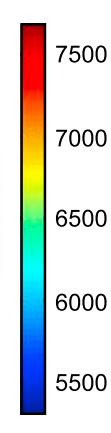

$\mathrm{ms}^{-1}$

\section{B Calcite}

\section{Crystallography}

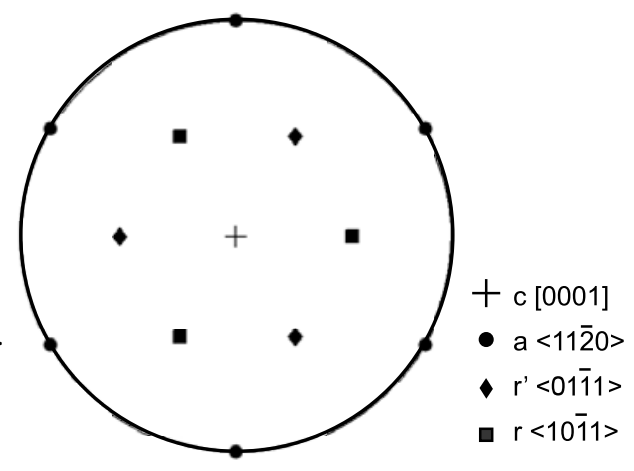

Anisotropy of $E 96.72 \%$

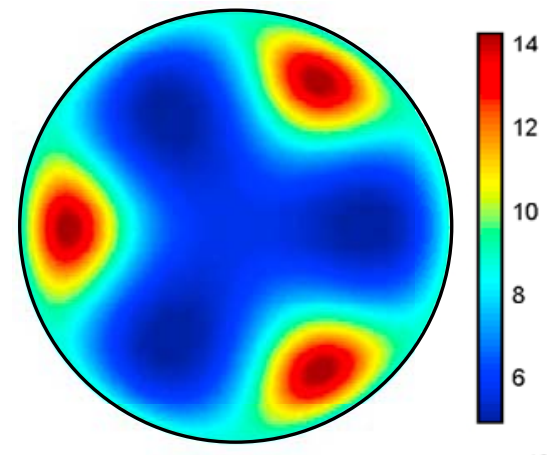

$\mathrm{Pa} \times 10^{10}$

$\mathrm{AV}_{\mathrm{p}} 32.29 \%$

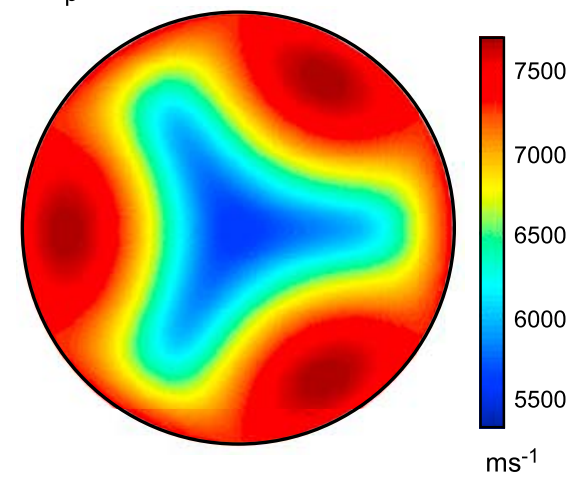

$\mathrm{AV}_{\mathrm{s}} 58.95 \%$

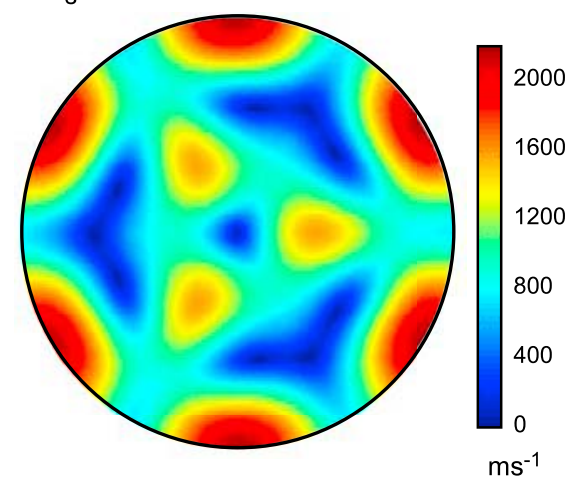

Figure 1 
sions. Two of the techniques most commonly used in earthquake seismology for the relative location of events are the master event and double-difference location algorithms. In both cases, the final location is obtained through the inversion of differential travel times with respect to one chosen master event (master event algorithm) or between all pairs of events within a cluster. Recent theoretical studies have shown for laboratory-scale studies that relative location methods can reduce significantly the location uncertainty even in a $40 \%$ anisotropic velocity structure using an isotropic model for location [Jones et al., 2008].

[6] The influence of anisotropy on the focal mechanisms of seismic events, including AE, has mainly been studied in the context of source mechanisms in anisotropic rocks. Source mechanisms can be thought of as differential force systems in isotropic media and are classified based on the volume change $(k)$ and deviatoric part of the moment tensor $(-2 \varepsilon)$ [Hudson et al., 1989; Julian et al., 1998]. Commonly described source mechanisms include double couple (DC), which consist of a pair of force couples with no net torque; isotropic (ISO), which include purely tensile opening or compressive closing of cracks (polarity dependent); vector dipole (VD) sources that are force dipoles with force directed outward or inward (polarity dependent); and compensated linear vector dipoles (CLVD) with force dipoles that are dominantly directed outward/inward (polarity dependent). Source mechanisms are commonly visualized on a $T-k$ plot [Hudson et al., 1989]. It is known that shear events in anisotropic media have non-double-couple (non-DC) components [Julian et al., 1998; Kawasaki and Tanimoto, 1981; Rössler et al., 2004; Vavryčuk, 2002, 2004; Vavryčuk, 2005]. Vavryčuk [2005] has shown that shear faulting in moderately anisotropic rocks can involve up to $\sim 30 \%$ CLVD and $\sim 15 \%$ ISO component in the moment tensor and even higher values for very anisotropic rocks such as schist, shale, and slate. If isotropy at the source region is assumed for moment tensor inversions, then predicted fault plane solutions can deviate from the true solution by up to $15 \%$ in moderately anisotropic rocks or provide completely misleading results in strongly anisotropic rock (see Julian et al. [1998] and Vavryčuk [2005] for a full discussion).

[7] In this contribution, we investigate the effects of elastic anisotropy in quartz on its brittle fracture behavior and on the relocation and source mechanisms of fracturerelated AE through a simple but well-constrained indentation experiment on a single quartz crystal at ambient pressure and temperature. The resultant cone crack morphology was analyzed using optical interferometry and scanning electron microscopy (SEM). Electron backscatter diffraction (EBSD) mapping of the crack tip damage zone provides insight into the microscale propagation mechanisms. The elastic energy released during the opening of the cone crack generated $\mathrm{AE}$, and these were recorded with ultrasonic sensors to monitor the fracturing process. Processing and modeling of the AE data reveals the effects of anisotropy on AE relocation and fracture source mechanisms.

\section{Analytical Techniques}

\subsection{Sample Description}

[8] The single crystal of natural Brazilian quartz used in this study was selected due to its large diameter (approximately $45 \mathrm{~mm}$ across) and an absence of visible inclusions, crystallographic defects, or preexisting fractures. A slab was cut normal (within $1^{\circ}$ ) to the $\langle c\rangle$ axis ( $z$ section) with a thickness of approximately $23 \mathrm{~mm}$. The sample faces were polished flat with progressively finer corundum grit (to grade 600) to remove surface aberrations and provide good contact with AE sensors. The top surface was further polished with progressively finer diamond paste to $1 \mu \mathrm{m}$ and then with $0.6 \mu \mathrm{m}$ colloidal silica $\mathrm{NaOH}$ suspension to remove fine-scale mechanical damage from previous polishing. An advantage of using a flaw-free single crystal of quartz is that the fracture geometry can be observed optically and used as benchmark for acoustic emission relocation. The flawless nature of the single crystal sample permits the isolation of the effects of the crystallographic anisotropy on brittle fracture and $\mathrm{AE}$.

\subsection{Experimental Procedure}

[9] The indentation experiment was performed using an Instron 4505 mechanical testing rig, housed in the Department of Engineering, University of Liverpool, UK. The sample was unconfined and uniaxially loaded parallel to the $\langle c\rangle$ direction using a spherical indenter at atmospheric laboratory temperatures $\left(\sim 25^{\circ} \mathrm{C}\right)$. The indenter comprised a $4 \mathrm{~mm}$ diameter hardened steel ball bearing embedded into a solid $50 \mathrm{~mm}$ diameter steel core (Figure 2). The indentation process was monitored using an array of pinducers to record AE events. The acoustic monitoring array consisted of 12 Valpey-Fisher VP-1093 piezoelectric pinducers. The pinducers were individually attached directly on to the polished surfaces and arranged radially around the perimeter of the sample at two different heights (tiers) to provide more complete coverage for $\mathrm{AE}$ events located in the sample center (Figures $1 \mathrm{a}$ and 2 ). The signal, with a preamplification of $40 \mathrm{~dB}$, was recorded using a Hyperion Ultrasonic Monitoring System [ESG, 2001] at a sampling frequency of $10 \mathrm{MHz}$. Due to the small scale of the expected fractures, the sensitivity of the system was set just above the background noise level at $50 \mathrm{mV}$ and an event was triggered when two or more sensors received a signal above this threshold voltage. This resulted in a large number of testing frame-induced noise, mainly from the friction between the ball and the crystal surface. These triggers were filtered out during the data processing. A velocity survey was performed immediately prior to the experiment, by pulsing from the

Figure 1. Crystallography and anisotropy of Youngs modulus $(E), P$ waves velocity $\left(\mathrm{AV}_{\mathrm{p}}\right)$ and $S$ wave velocity $\left(\mathrm{AV}_{\mathrm{s}}\right)$ for (a) single crystal quartz and (b) single crystal calcite. Calculated from the elastic stiffness data of Hearmon [1956]. Ray path orientations to pinducers used in the experiment on quartz from an AE event sourced in the center of the sample and are shown superimposed on to the seismic velocity anisotropy. This indicates the focal coverage of the experimental setup. Lower hemisphere, equal area projections. 

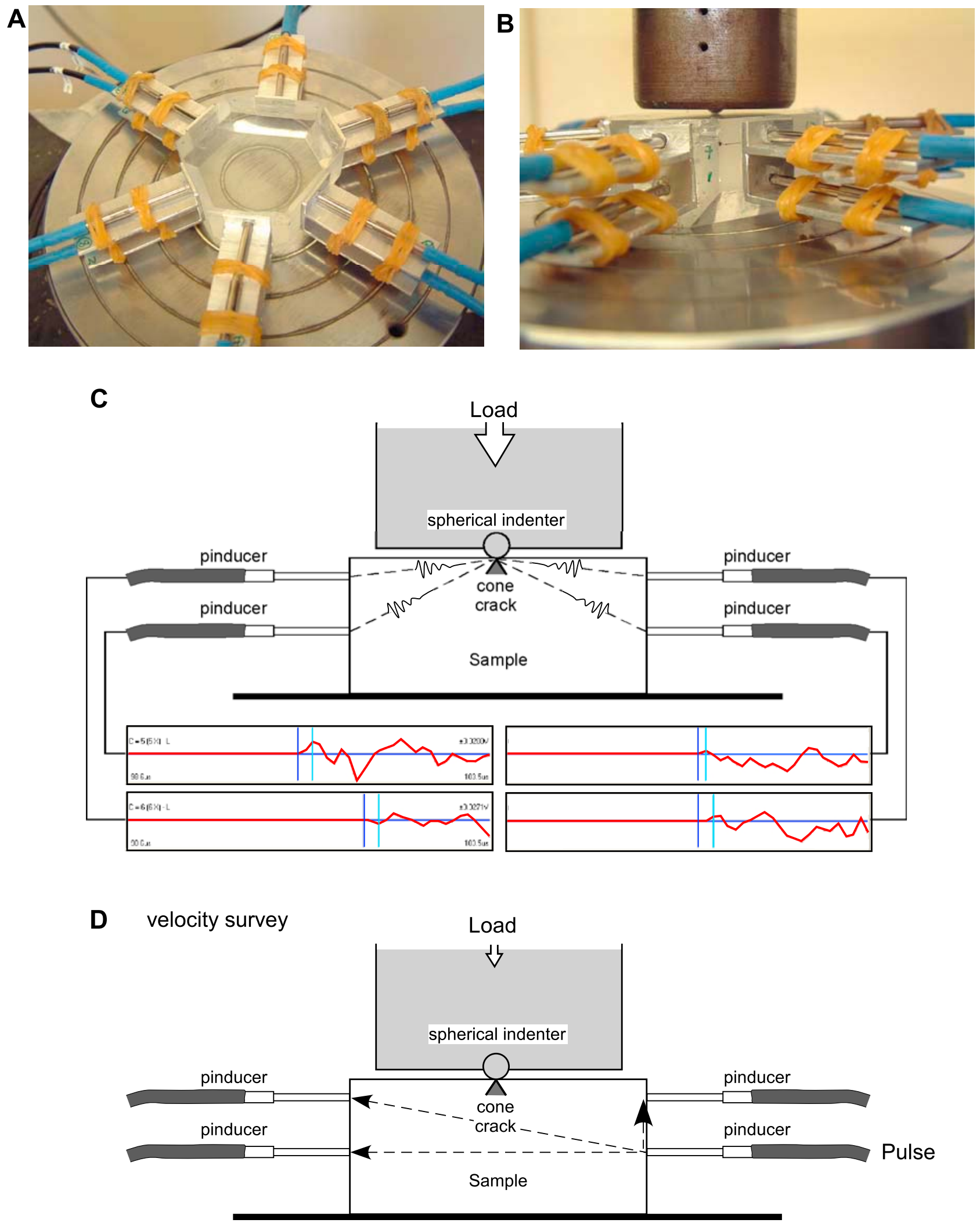

Figure 2. Experimental setup. (a) Photograph showing the geometry of the pinducer array. (b) Photograph of the sample during experimental loading. (c) Diagram showing the loading and sensor geometry of the experiment. Dashed lines show the acoustic emission raypaths from source below the indenter. (d) Diagram showing the raypaths during velocity surveys. Example oscillograms show $P$ wave first arrival (deep blue) and first peaks (mid blue) in $4.9 \mu$ s windows. 
A

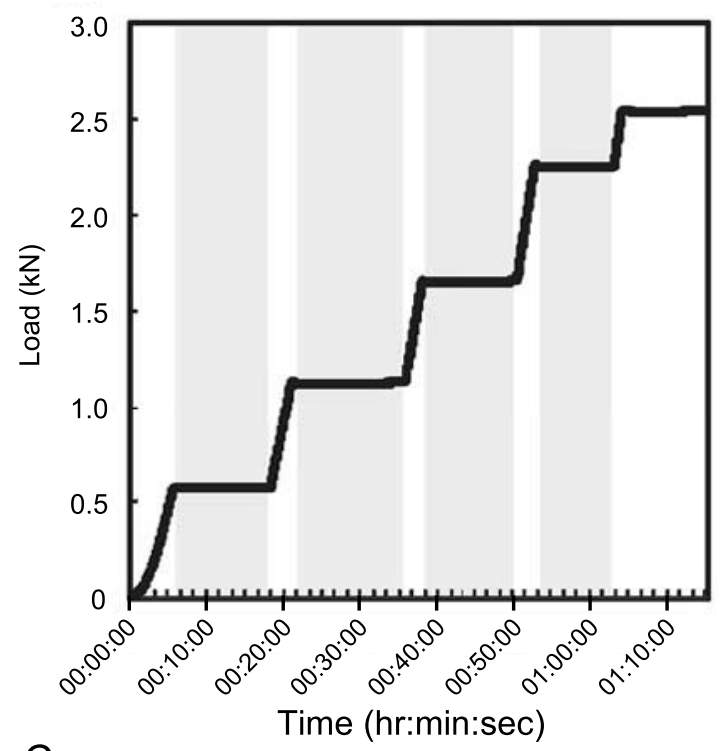

$\mathrm{C}$

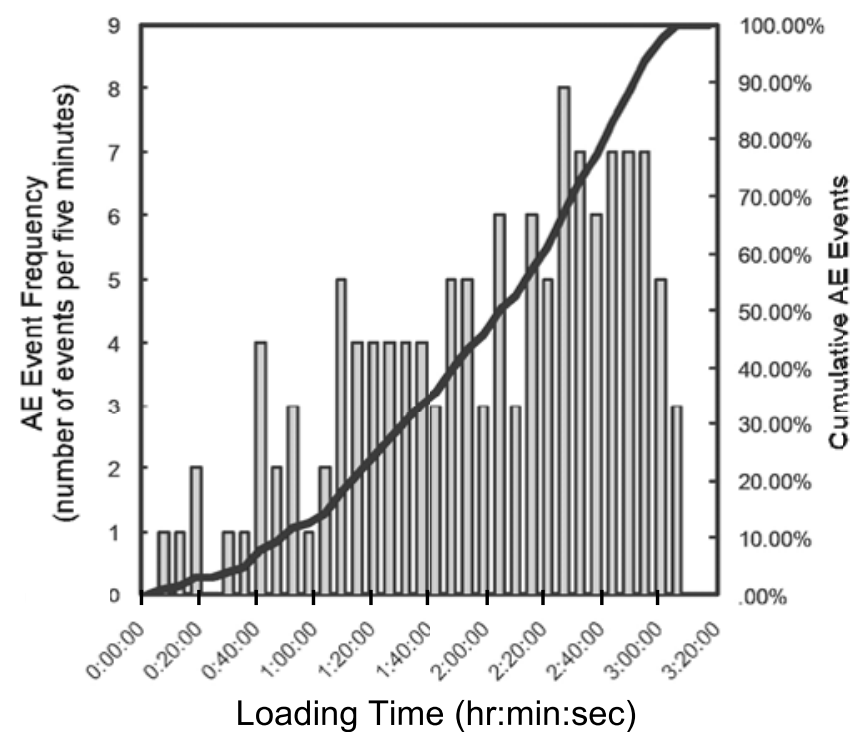

B

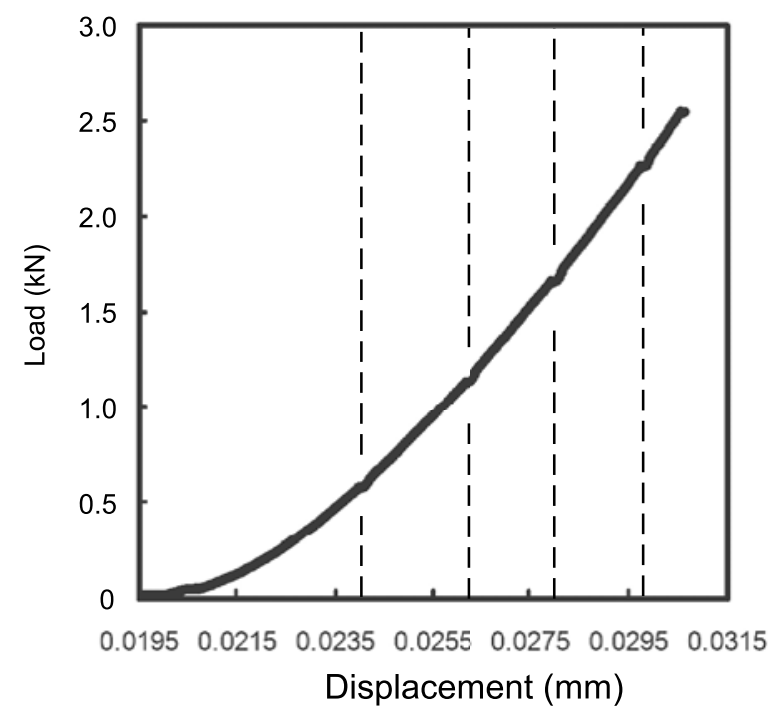

D

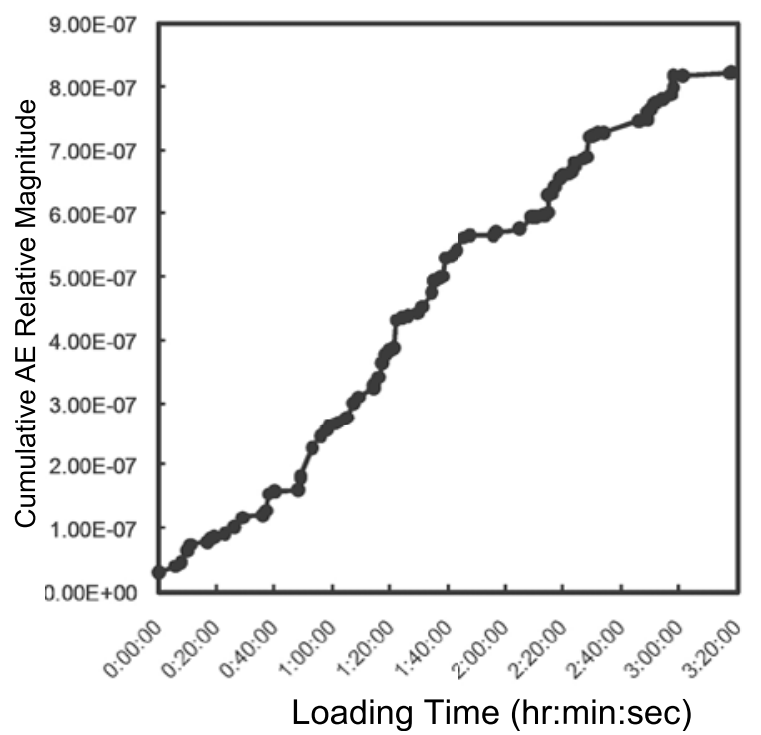

Figure 3. Evolution of stress, strain, and acoustic emission (AE) during the experiment. (a) Load history of the sample. Intervals indicated by gray boxes depict velocity surveys during which the displacement rate was reduced to $0.001 \mathrm{~mm} / \mathrm{min}$. (b) Load versus displacement graph shows quasi-linear response after initial loading of $\sim 0.4 \mathrm{kN}$. Dashed lines show intervals of low loading rate during velocity surveys. Displacement was negligible during these intervals. (c) Chart of acoustic emission events and (d) acoustic emission relative magnitudes (inverse log) accumulated over time during high displacement rate (loading time), with time spent at low displacement rate during velocity surveys omitted.

lower pinducers in six different directions. Two pencil lead break tests were conducted prior to loading to aid subsequent calibration of AE source locations. The energy released by breaking a retractable pencil lead against the sample surface has similar source dimensions and magnitude to that of microcracks, and marks left on the sample allow accurate testing of AE location algorithms.

[10] The sample was loaded with an initial displacement rate of $0.1 \mathrm{~mm} / \mathrm{min}$. At every $\sim 1 \mathrm{kN}$ of applied load, the displacement rate was slowed to $0.001 \mathrm{~mm} / \mathrm{min}$ to perform velocity surveys in six directions before the loading rate was restored to $0.1 \mathrm{~mm} / \mathrm{min}$ (Figure 3a). A total of five velocity surveys were performed at different loads to determine any changes in the velocity structure during the deformation. Negligible displacement and no acoustic emission events occurred during the velocity surveys at low displacement rates or during the unloading part of the experiment (Figure 2b). Differences in $P$ wave first arrivals during velocity surveys indicate a similar range in absolute $P$ wave velocities and comparable velocity anisotropy structure (up to $33 \% \mathrm{AV}_{\mathrm{p}}$ ) that mimics that calculated from elasticity data (Table 1; Figure 1). Uncertainties in the measured absolute 
Table 1. $P$ Wave Velocity Survey Conducted on the Sample at Zero Load, Pulsing From Different AE Sensors ${ }^{\mathrm{a}}$

\begin{tabular}{|c|c|c|c|c|c|c|c|c|c|c|c|c|c|}
\hline \multirow{3}{*}{$\begin{array}{l}\text { Pulse Sensor } \\
\text { (Lower Tier) }\end{array}$} & \multicolumn{13}{|c|}{ Receiver Sensor } \\
\hline & \multicolumn{6}{|c|}{ Lower Tier } & \multicolumn{7}{|c|}{ Upper Tier } \\
\hline & 1 & 2 & 3 & 4 & 5 & 6 & 7 & 8 & 9 & 10 & 11 & 12 & Survey Mean \\
\hline 1 & $\mathrm{X}$ & 6153 & 6298 & 5872 & 6339 & 5987 & $\mathrm{X}$ & $4532^{\mathrm{b}}$ & 6302 & 6381 & 6253 & 6093 & 6021 \\
\hline 2 & 5368 & $\mathrm{X}$ & 5950 & 5649 & 5585 & 5717 & 6517 & $\mathrm{X}$ & 5912 & 5671 & 5376 & 5678 & 5742 \\
\hline 3 & 5908 & 5936 & $\mathrm{X}$ & 5536 & 5870 & 5767 & 6016 & 5637 & $\mathrm{X}$ & 4075 & 5708 & 6089 & 5654 \\
\hline 4 & 5719 & 5836 & 5560 & $\mathrm{X}$ & 5689 & 5893 & 5411 & 5798 & 6528 & $\mathrm{X}$ & $6729^{c}$ & 5723 & 5889 \\
\hline 5 & 5888 & 5653 & 5773 & 5484 & $X$ & 5697 & 5850 & 5773 & 5911 & 5072 & $\mathrm{X}$ & 5430 & 5653 \\
\hline \multirow[t]{2}{*}{6} & 5375 & 5706 & 5775 & 5726 & 5740 & $\mathrm{X}$ & 6260 & 5727 & 5507 & 5780 & 6482 & $\mathrm{X}$ & 5808 \\
\hline & & & & & & & & & & \multicolumn{3}{|c|}{ Overall mean } & 5795 \\
\hline
\end{tabular}

${ }^{\text {a }}$ Sensor numbers as in Figure 1 . Velocities are in $\mathrm{ms}^{-1}$. Mean $V_{\mathrm{p}}$ for the survey is $5795 \mathrm{~ms}^{-1}$, and $P$ wave velocity anisotropy $\left(\mathrm{AV} \mathrm{V}_{\mathrm{p}}\right.$ ) is $33 \%$.

${ }^{\mathrm{b}}$ Minimun velocity.

${ }^{\mathrm{c}}$ Maximum velocity.

velocities are better than $2.5 \%$, based on reproducibility of velocity surveys to opposing sensors at constant load. No significant changes in velocity were detected (beyond analytical uncertainty) during loading and unloading. The experiment was terminated at $2.5 \mathrm{kN}$ load $(\sim 2.5 \mathrm{~mm}$ displacement) without any bulk failure of the sample.

\subsection{Characterization of Fracture Geometry and Crack Tip Damage}

[11] The surface topography of the quartz crystal generated during the experiment was measured using a Veeco optical interferometer at the Department of Mechanical Engineering, University of Liverpool. This technique combines rapid acquisition of high vertical resolution $(<0.5 \mathrm{~nm})$ surface profiles with a vertical range of several millimeters and a field of view of tens of millimeters. Side faces of the sample were polished to allow photographic images to be taken of the fracture. In order to examine the morphology of the subsurface fracture(s), the sample was carefully cut normal to the indented surface across the diameter of the cone crack. The newly sectioned surface was polished flat with colloidal silica $\mathrm{NaOH}$ suspension to remove mechanical damage from the saw. Backscatter electron (BSE) images were taken of this surface using a CamScan X500 crystal probe field emission SEM using $20 \mathrm{kV}$ accelerating voltage. The damage zone ahead of the crack tip was characterized by electron backscatter diffraction (EBSD) mapping [Prior et al., 1999, 2009] using Oxford Instruments (formerly HKL Technology) Channel 5 acquisition system. Electron backscatter patterns (EBSPs) were collected on a $931 \times 210$ pixel grid with $1 \mu \mathrm{m}$ pixel spacing. The seven most intense Kikuchi bands were automatically detected from a Hough transform of the EBSPs and automatically indexed using a theoretical reflector intensity file with structural parameters (e.g., space group, atom coordinates, and occupancy) derived for quartz, optimized for correct indexing of left-handed versus right-handed quartz. Indexing solutions with a mean angular deviation of $>1^{\circ}$ were rejected, and approximately $70 \%$ points were successfully indexed. EBSD map and pole figure data were processed using the "Tango" and "Mambo" modules of the Channel 5 software, respectively. Band contrast is a measure of the intensity of Kikuchi bands in EBSPs and is obtained from the contrast identified in the Hough transform. Band contrast is a fundamental property of an EBSP and is dominated by crystallographic/structural integrity but can also vary with crystallographic orientation and surface topography. In the absence of orientation and surface topography variations, reductions in band contrast can be used as a qualitative proxy for crystallographic damage [Cayzer et al., 2008; Lehockey et al., 2000; Nemchin et al., 2009; Tucker et al., 2000; Wilkinson, 2000].

\subsection{Acoustic Emission Processing Techniques}

[12] Two location methods were used for the processing of the recorded events: an iterative Geiger absolute location and a master event relative location. For the Geiger routine, a single $P$ wave velocity of $6000 \mathrm{~m} / \mathrm{s}$ was chosen for the optimal location of the pencil lead break on the top surface of the sample before indentation. This velocity approximates the mean velocity sampled by the transducers assuming an $\mathrm{AE}$ event in the foci of the array at the sample surface. As presented by Mainprice and Casey [1990] and Lloyd and Kendall [2005], the velocity of both $P$ and $S$ waves propagating through a single quartz crystal depends highly on the orientation of the ray with respect to its crystallographic axes. This anisotropy is in the order of $27 \%$ for $P$ wave velocity and $43 \%$ for $S$ wave velocity.

[13] The master event relative location approach effectively reduces the uncertainties caused by a poor knowledge of the complexities in the velocity structure. The method adjusts the locations of the events relative to a master event location, which is assumed to be accurate, reducing the raypaths involved in the location to a small volume containing the master and process events (cluster). When an accurately surveyed master (e.g., pencil lead break, hit) is not available, any absolute location uncertainty in the master is transmitted to the absolute location of the cluster. The increase in accuracy is achieved within the cluster, enhancing the resolution of the internal distribution of the events within the cluster. Since this technique only depends on the seismic velocity within the cluster volume, it is unlikely that the internal distribution of the cluster is strongly dependent on the master selection. The two effects on the master selection are the absolute positioning of the seismic cluster and the determination of arrival time differences (the clearer the signal, the more precise this can be performed). It is expected that the effect of selecting a different master with equal signal quality will be a different positioning of the cluster but a similar internal distribution. Relative location has been extensively applied at different 
scales, from tectonic earthquakes [e.g., Deichmann and Garcia-Fernandez, 1992; Rietbrock et al., 1996] to regional and mine scales [e.g., Phillips et al., 1997; Reyes-Montes et $a l ., 2005]$, reducing hypocentral uncertainties by an order of magnitude and improving the definition of natural and induced geological structures.

[14] This method assumes that the raypaths from closely located events to the sensors have approximately the same takeoff angle and traverse the same velocity structures. This approximation is valid provided that the event separation is much smaller than the distance to the array sensors. Under this assumption, the common trajectories in the travel time equation cancel out, and locations can be calculated as deviations from the location of one master event (equation (1)). With this approach, differential travel times only depend on the seismic wave velocity in the volume between the master event and the relocated event and their relative position to each other [Yang et al., 2002]. In this way the effect of any strong anisotropy is reduced to the relatively small volume containing the events.

[15] For master event relative location, $P$ wave onsets were measured for all the recorded events and used to invert for the source location by solving the set of equations:

$$
\delta t_{i}=\left(\nabla \cdot T_{i}\right) \cdot \delta \theta_{0},
$$

where $\delta t_{i}$ is the arrival time difference calculated for station $i$, $T_{i}$ is the travel time equation, and the partial derivatives in the $\nabla$ operator are calculated at the master event coordinates. The solution vector $\delta \theta_{0}$ corresponds to the deviation of the process event hypocenter relative to the location of the master event.

[16] Moment tensors for the observed AE events have been decomposed using the method of Knopoff and Randall [1970]. The more commonly used Harvard method employed in the CMT data base [Dziewonski et al., 1987] seeks to maximize the double-couple (DC) component based on a widely held belief that shear processes are likely to dominate at the source region. However, source mechanisms involving dilatation (positive or negative), with or without a component of shear, are theoretically possible and have been observed in natural events [Julian et al., 1998; Miller et al., 1998]. As noted in section 1, even 100\% shear (DC) source mechanisms in anisotropic rocks can produce nonDC components in the moment tensor [Vavryčuk, 2005]. For our AE events produced in elastically anisotropic quartz, we prefer the rationale behind the Knopoff and Randall [1970] method, which finds DC and CLVD components with common $P$ and $T$ axes rather than assuming the source mechanism is dominated by shear. For AE events with nonzero DC components in the moment tensor, the source type plot can be used to discriminate between different kinds of focal mechanism [Hudson et al., 1989]. The axes of this plot are $T$ and $k$, which are defined as

$$
\begin{gathered}
T=-\mathbf{M}^{\mathrm{CLVD}} /\left|\mathbf{M}^{\mathrm{DC}}+\mathbf{M}^{\mathrm{CLVD}}\right|, \\
k=\mathbf{M}^{\mathrm{ISO}} /\left(\left|\mathbf{M}^{\mathrm{ISO}}\right|+\left|\mathbf{M}^{\mathrm{max}}\right|\right),
\end{gathered}
$$

where $\mathbf{M}^{\max }$ is the largest eigenvalue of the deviatoric (DC + CLVD) moment tensor. The vertical axis $(k)$ measures the dilatational isotropic component, either +ve for expansion or $-v e$ for contraction, and the horizontal axis $(T)$ measures the deviatoric component.

\subsection{Modelling of AE Source Mechanisms in an Anisotropic Medium}

[17] Inferring the actual source mechanisms from the observed moment tensors is inherently nonunique. Therefore, we have calculated moment tensors for synthetic events with prescribed source tensors using the known elastic stiffness values of quartz and calcite for comparison [Hearmon, 1956]. The source tensor describes the geometry and kinematics of the fracture at the source region. Varying the source tensor and keeping the elastic stiffness constant allow us to explore the effect of different fracture kinematics (e.g., opening mode and shear mode) on the decomposed components of the moment tensor. To calculate the synthetic moment tensors, we used the expressions in the work of Vavryčk [2005], and as for the observed events, we decomposed these using the method of Knopoff and Randall [1970].

[18] The moment tensor $\mathbf{M}$ of a seismic event can be expressed as

$$
M_{i j}=u A \mathbf{c}_{i j k l} \boldsymbol{\nu}_{k} \mathbf{n}_{l},
$$

where $u$ is the slip, $A$ is the area of the fault or crack, $\mathbf{c}$ is the elastic stiffness tensor, $\boldsymbol{\nu}$ is the slip vector, and $\mathbf{n}$ is the normal to the fault or crack [Aki and Richards, 2002]. Using the relation

$$
\mathbf{D}_{k l}=(1 / 2) u A\left(\nu_{k} n_{l}+\nu_{l} n_{k}\right)
$$

where $\mathbf{D}$ is the seismic source tensor, we can simplify equation (4) to

$$
M_{i j}=\mathbf{c}_{i j k l} \cdot \mathbf{D}_{k l} .
$$

For the case of elastic isotropy, $\mathbf{c}$ can be simplified to two distinct values (e.g., Young modulus and Poisson's ratio, or the two Lamé constants), but equation (6) describes the general case for a seismic source in a homogeneous medium of any elastic symmetry.

[19] The moment tensor $\mathbf{M}$ can be thought of as comprising three components, some of which can be 0 for certain special configurations of elastic stiffness and source tensor. These components are the DC, ISO, and the CLVD. Following Vavryčuk [2005], we can write

$$
\mathbf{M}=\mathbf{M}^{\mathrm{ISO}}+\mathbf{M}^{\mathrm{CLVD}}+\mathbf{M}^{\mathrm{DC}}
$$

\section{Results}

\subsection{Cone Crack Geometry and Fracture Pattern}

[20] Loading the quartz crystal with a spherical indenter to $2.5 \mathrm{kN}$ resulted in the generation of a cone crack visible to $\sim 7 \mathrm{~mm}$ beneath the sample surface and a quasi-concentric set $(n=87)$ of smaller peripheral subsidiary cracks, synthetic to the larger cone crack, and penetrating $<1 \mathrm{~mm}$ into the sample (Figure 4). This forms the vast majority of the 

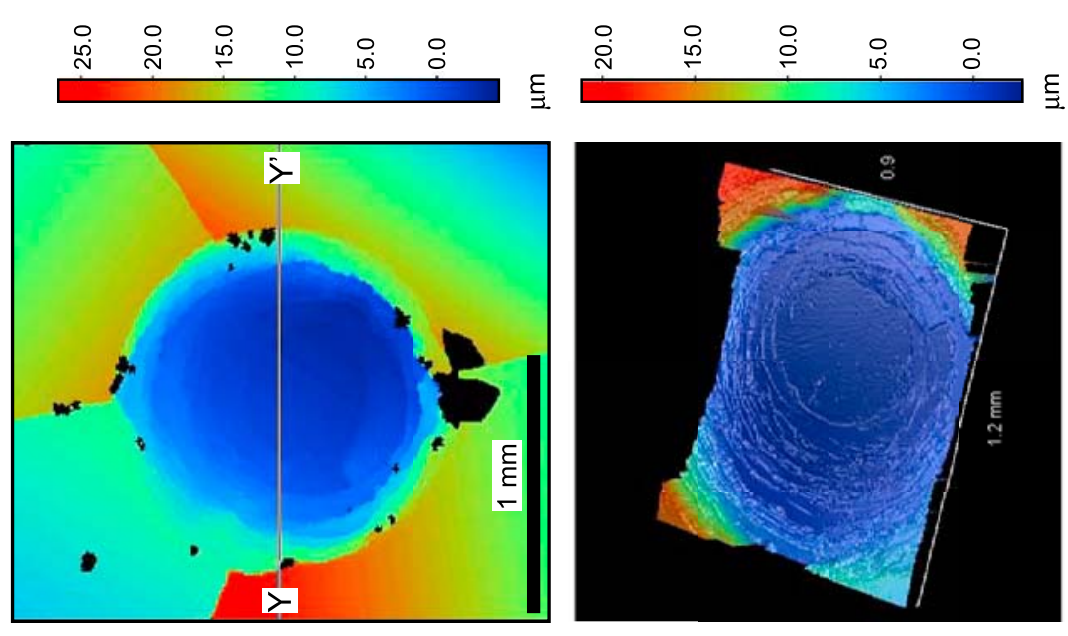

0
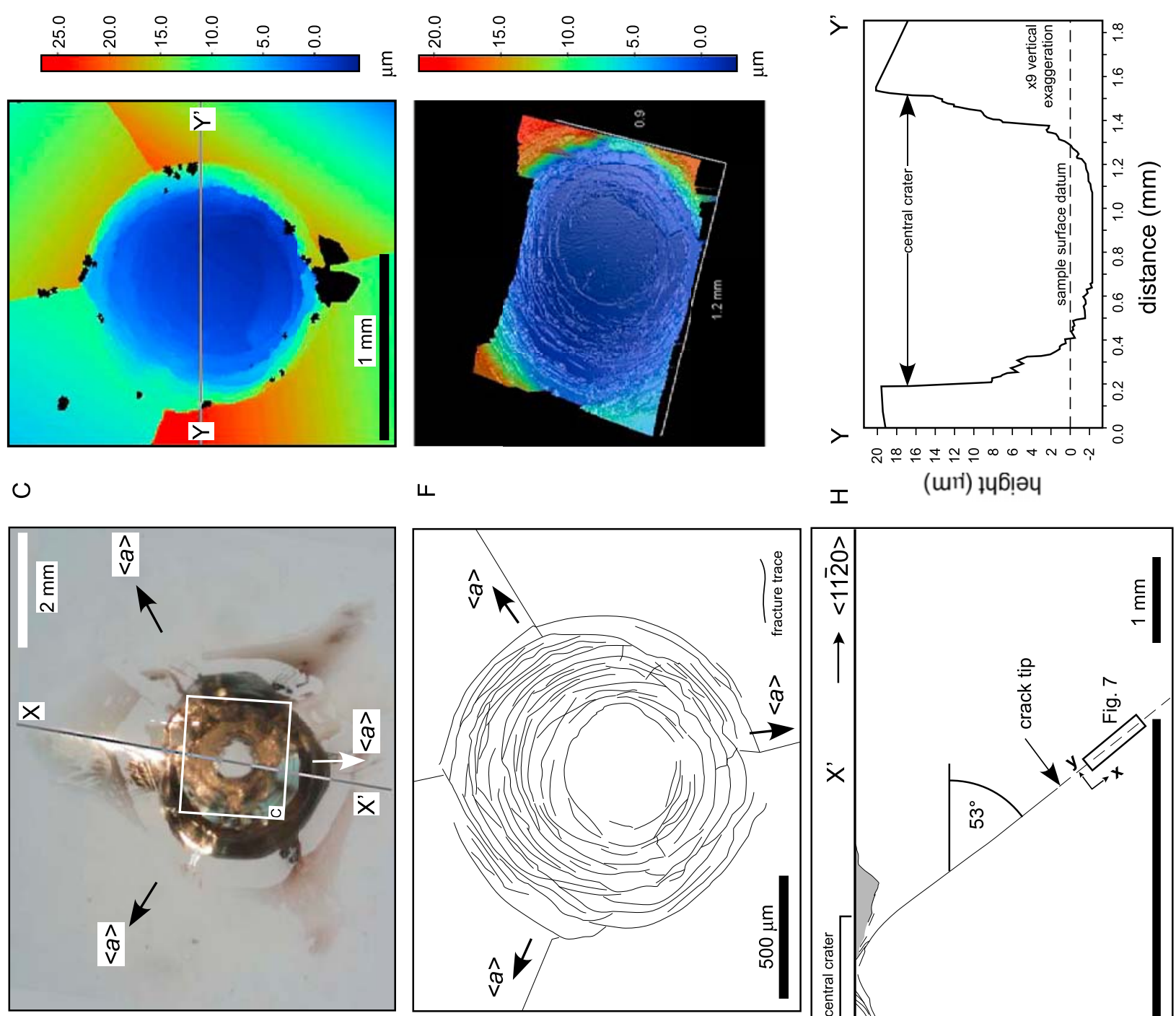

ᄂ
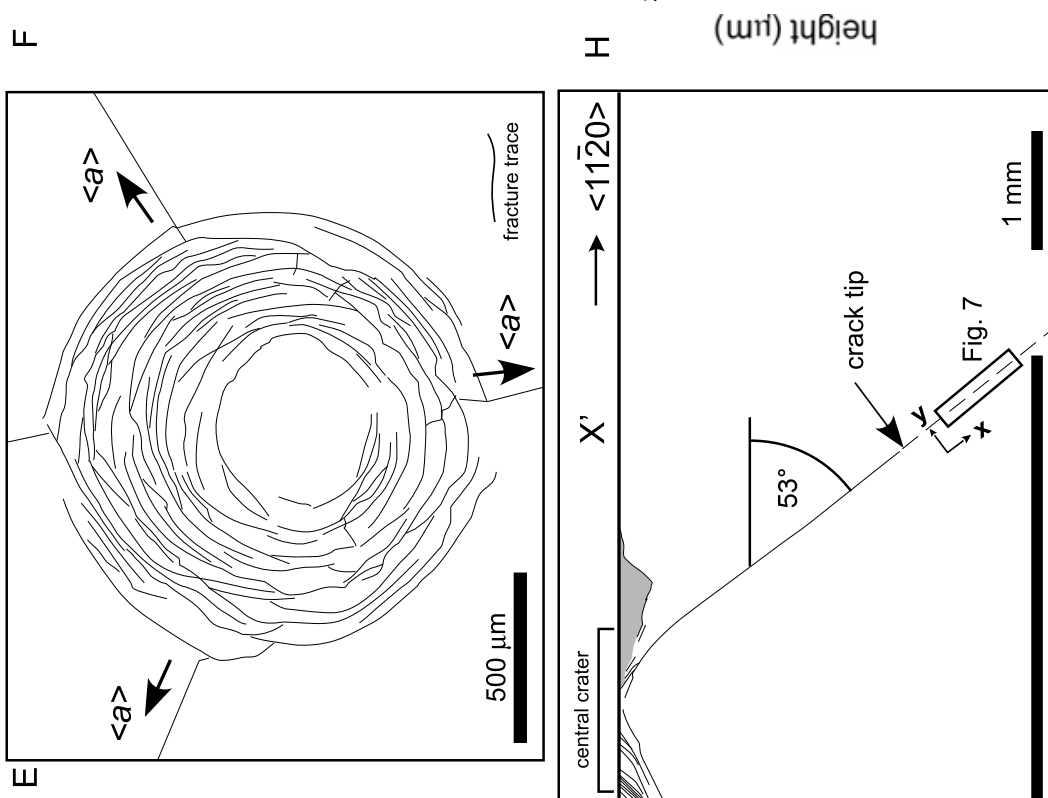

$\infty$
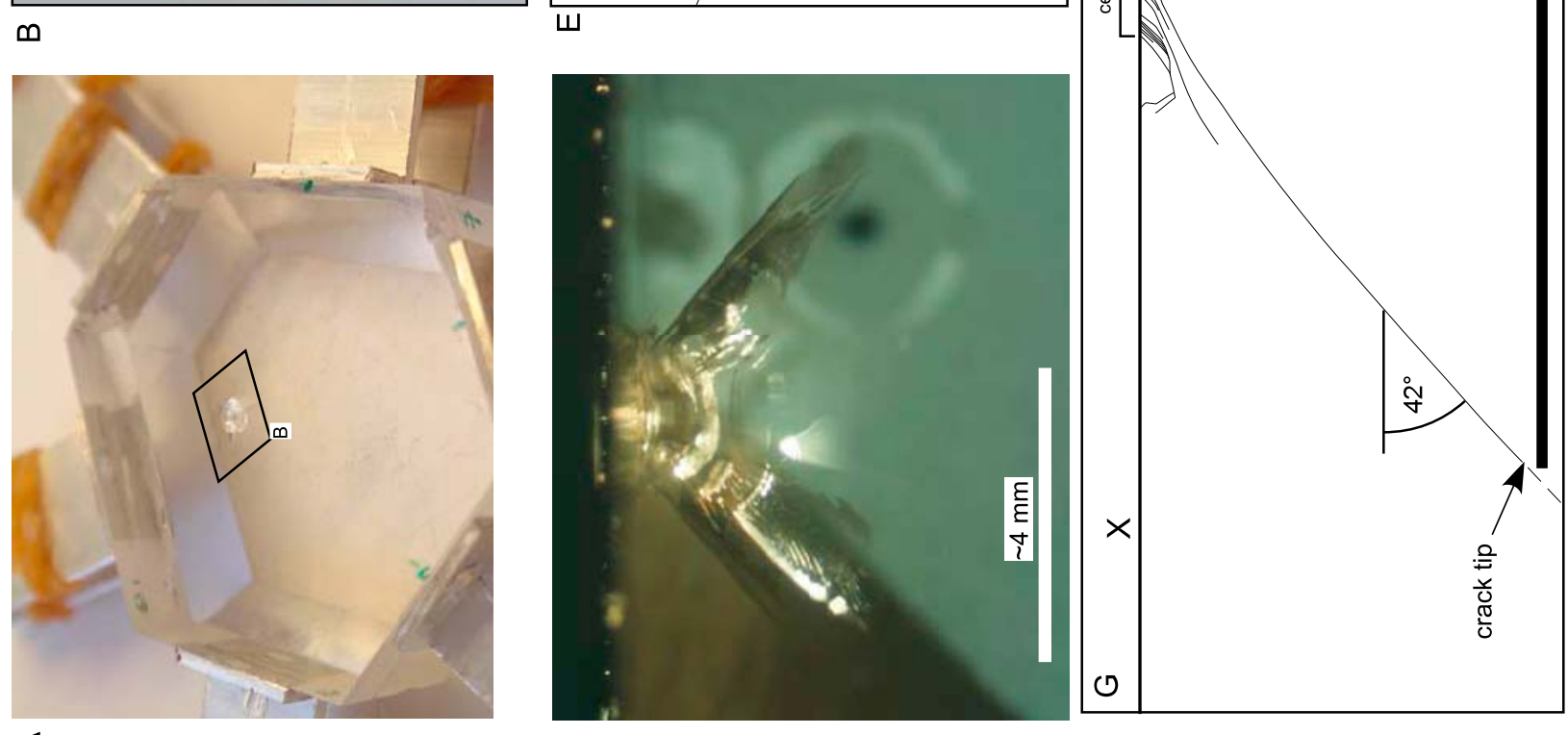

$\varangle$

๑ 
crack damage in the sample. Optical interferometry of the sample surface after loading reveals that the subsidiary quasi-concentric cracks form a damage crater of $22 \mu \mathrm{m}$ depth, at the point of loading, and are surrounded by uplifted flanges accommodated by four steeply dipping radial cracks (Figure 4c). Vertical displacement across the concentric cracks ranges from 0.5 to $10 \mu \mathrm{m}$ and varies with position relative to the crater center, with highest displacements across fractures toward the outer rim of the crater. In profile, these cracks link smoothly at depth with a few shallowly dipping inner cracks. Steeply dipping fractures link the tips of the shallow dipping fractures to the sample surface and presumably accommodate the body rotation indicated by surface tilting of the uplifted flanges (Figures $4 \mathrm{c}$ and $4 \mathrm{e}$ ).

[21] The morphology of the optically visible cone crack shows radial variations in apical angle and length and shows distinct trigonal symmetry (Figure $4 \mathrm{~b}$ ). The longest fracture length $(\sim 5 \mathrm{~mm})$ corresponds with the shallowest dip angle $\left(\sim 40^{\circ}\right.$; Figure $\left.4 \mathrm{~g}\right)$. The surface of the cone crack appears to vary smoothly in orientation between three shallower dipping cusps (Figure $4 b$ ).

\subsection{Location of Acoustic Emission Events}

[22] A total of $94 \mathrm{AE}$ events with a high signal-to-noise ratio were selected for analysis. The generation rate of these $\mathrm{AE}$ events steadily increased over the duration of the experiment (Figure $3 \mathrm{c}$ ). The $\mathrm{AE}$ event magnitudes range from -5.3 to -4.6 and were calculated using the relative magnitude method described by Thompson et al. [2006]. Since the magnitude scale is logarithmic, Figure $3 \mathrm{~d}$ presents a cumulative plot of the inverse logarithm of the magnitudes, which depicts a quasi-linear response over time. Each AE event has a clear $P$ wave onset, which was manually picked and used for source locating. $S$ wave arrivals occurred within the $P$ wave coda and were not used. An event induced at an early stage of the indentation, located close to the surface (where fracture damage was observed), and with the highest signal-to-noise ratio was chosen as reference (master) event for the relative location. The results of the locations using both absolute and relative locations are compared in Figure 5 together with a wire frame outline of the sample. Locations using both methods appear to be well constrained in the horizontal coordinates $(x, y)$, defining an area similar to that occupied by the cone fracture. The temporal pattern shows seismicity tightly clustered in the initial stages, spreading radially from the initial location as the cone crack develops in the later stages of the experiment. In the vertical coordinate $(z)$, however, there is an unrealistically large scatter in the absolute locations, showing seismicity in regions not visibly affected by fracture. This can be attributed to a higher impact of the velocity anisotropy in the vertical dimension, with most of the events locating up to $5 \mathrm{~mm}$ below the observed fracture. The vertical scatter is not as large in the relative located events, with most events locating within the vicinity of the cone fracture surface with a scatter $<2 \mathrm{~mm}$. The location results correlate reasonably well, both vertically and horizontally, to the extent of the observed cone crack (Figure 4).

\subsection{Resolving Acoustic Emission Source Mechanisms 3.3.1. Moment Tensors From Measured AE Events in Quartz}

[23] A robust moment tensor calculation requires unambiguous determination of the initial sense of motion and amplitude recorded at each sensor, as well as good focal sphere coverage of sensors around the source. The method used is described further by Collins et al. [2002]. Moment tensors were determined with confidence for 65 of the 94 events located using both the Geiger and "master event" routines (Figures 6 and 7). The events relocated using the Geiger routine show a trimodal end-member behavior in the isotropic (ISO) component, with peaks at $+30 \%, 0 \%$, and $-30 \%$, such that they plot along a trend from + ve to $-v e$ vector dipole on a $T-k$ diagram, with some double-couple events (Figure 6). The data also show that the plunge of intermediate $(B)$ axes is consistently subhorizontal $\left(<10^{\circ}\right)$ and that $T$ axis plunge range between 0 and $90^{\circ}$ (Figures $6 \mathrm{~d}$ and $6 \mathrm{f}$ ). There is a strong preferred orientation of the $B$ axes toward $\sim 045^{\circ}$ azimuth, with a minor cluster at $\sim 120^{\circ}$ azimuth. The $120^{\circ}$ cluster aligns with the crystallographic $m$ direction, but the $\sim 045^{\circ}$ data do not align with any specific crystallographic direction (Figure $6 \mathrm{~d}$ ). The $\sim 045^{\circ}$ cluster contains both $+v e$ and -ve ISO components. Discounting the few events with intermediate values for $B$ axis azimuth, ISO component, and $T$ plunge, the majority of the AE events fall into four different source types, represented approximately evenly in the data (Figure 6a). The same events relocated using the master event technique yield source mechanisms along a similar trend but with greater certainty than the Geiger relocated events. The key differences are that these events are bimodal, cluster more tightly at +ve and -ve vector dipole, and with no DC events (Figure 7). This is shown by a stronger ISO component, with most events $\sim 40 \%$ ISO (Figure 7e). The plunge and trend of the $P$ and $T$ axes located using the master event-relocated events show a

Figure 4. Images depicting the morphology of the experimentally produced cone crack and related fracture damage. (a) Oblique view of the sample with cone crack visible at center. The sample is approximately $45 \mathrm{~mm}$ across. (b) Plan view showing cone crack outlined by box in Figure 4a. Lighting variations depict morphological variations of the crack surface with clear trigonal symmetry. Crystallographic $\langle a\rangle$ directions are indicated by arrows. (c) Surface elevation map of the central damage region from optical interferometry. Datum is the bulk crystal surface height. A central crater containing multiple curved quasi-concentric fracture traces is surrounded by marginal tilted and uplifted flanges. (d) Photograph of a side view of the cone crack. (e) Map of the fracture pattern from the central crater. Eighty-seven individual fracture traces have been identified from Figure 4c. (f) Three-dimensional morphology of the central crater from optical interferometry. (g) Sketch of a vertical profile through the center of the cone crack from SEM imaging of the surface of a section cut along $X-X^{\prime}$ in Figure 4b. Boxed area shows location and $x-y$ orientation of Figure 7. (h) Plot of the surface elevation along profile $Y-Y^{\prime}$ in Figure 4c. 

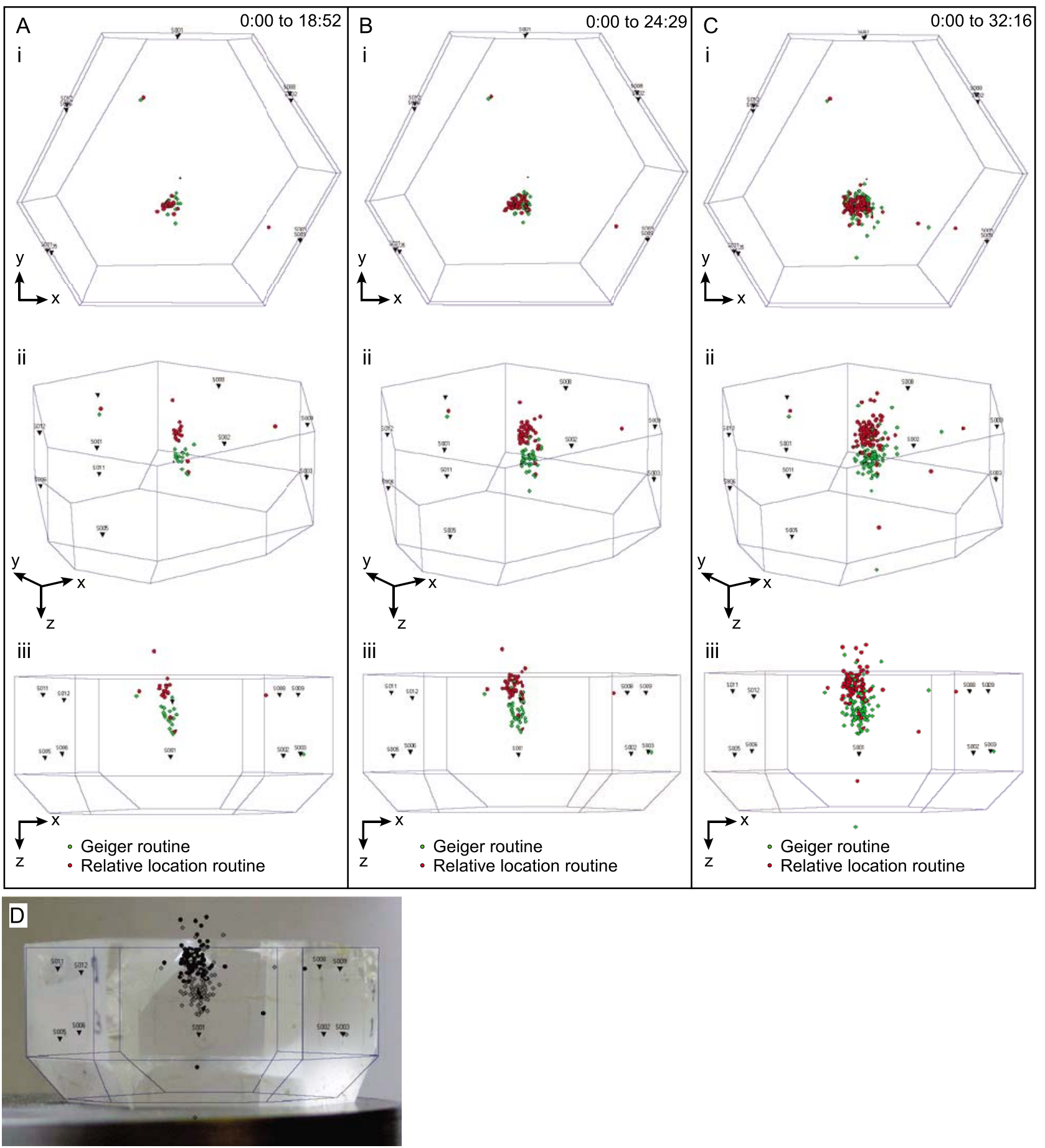

Figure 5. $(\mathrm{a}-\mathrm{c})$ Views of the cumulative $\mathrm{AE}$ events recorded during the blunt indentation experiment over time. A total of 94 source events were successfully located using the Geiger routine (green circles) and relatively located (red circles) using an early master event located at the upper surface of the sample. (d) Side view of the quartz sample showing the location of the acoustic emissions following the master relative location. The events show a good agreement with the observed cone fracture.

broadly similar distribution to the Geiger relocated events (Figures $7 \mathrm{f}$ and $7 \mathrm{~g}$ ).

[24] The Geiger relocated events show a pattern in the initial stages of loading, with the first six events consistently having a strong negative isotropic (anticrack) and steeply plunging $T$ axis components (Figures $6 \mathrm{c}$ and $6 \mathrm{~d}$ ). For most of the duration of the experiment, there was no systematic pattern of isotropic mode, with a mixed distribution +ve and - ve ISO events that appears to switch at random. The last $\sim 9$ events during the loading history have a +ve ISO compo- 
A

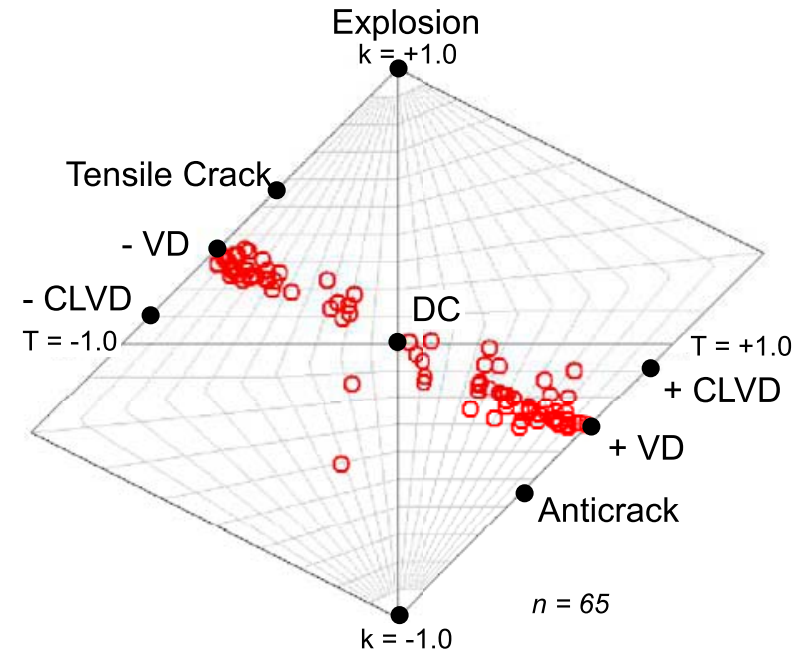

$c$

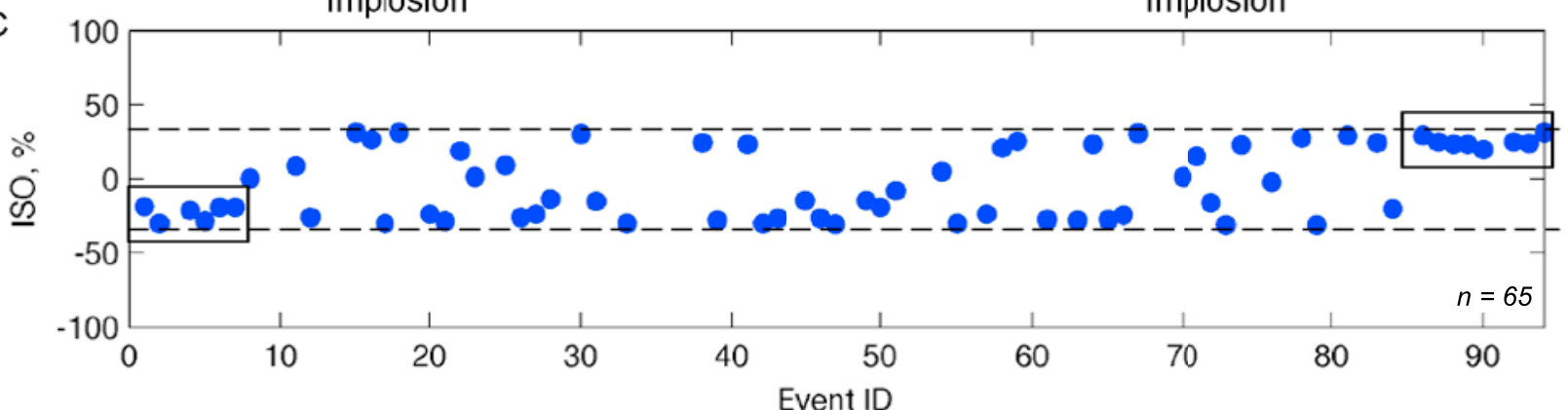

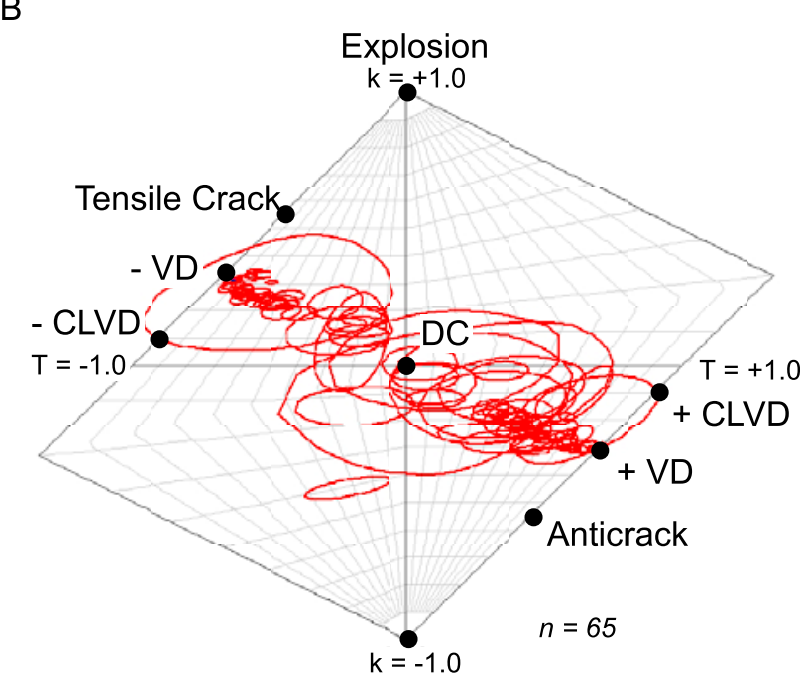

Implosion

D

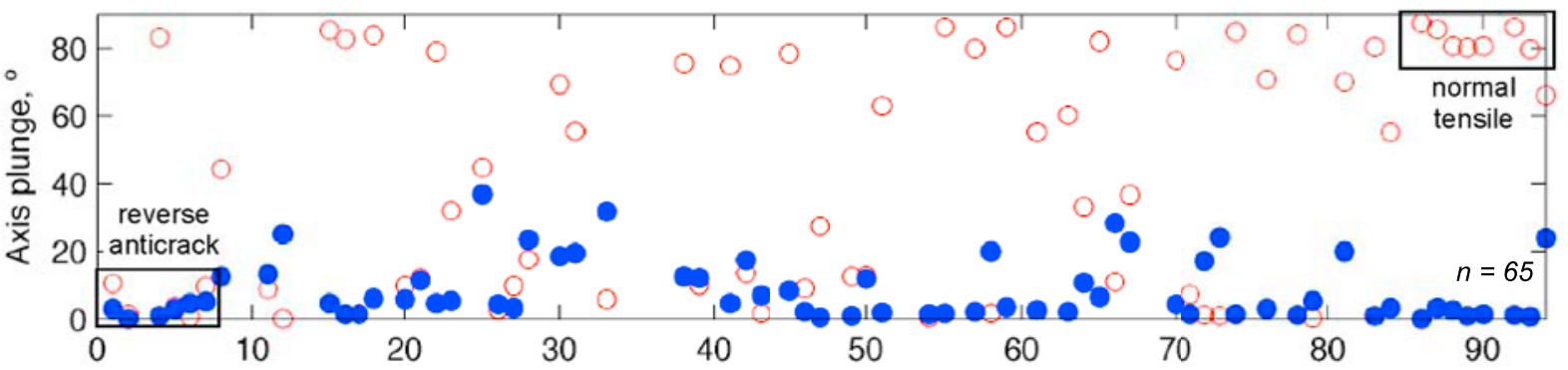

E

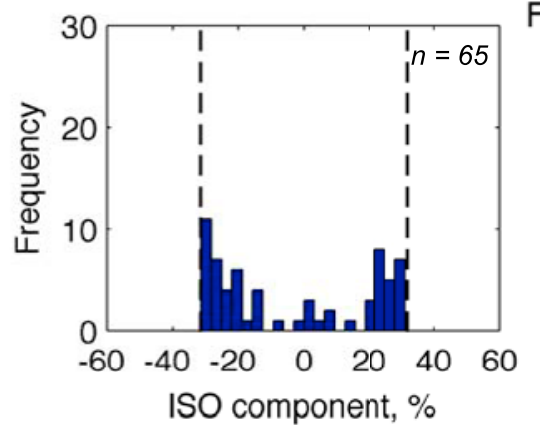

$\mathrm{F}$

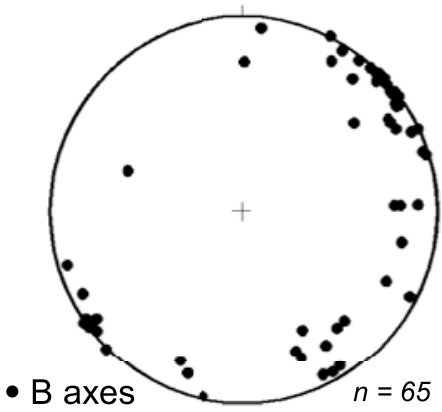

G

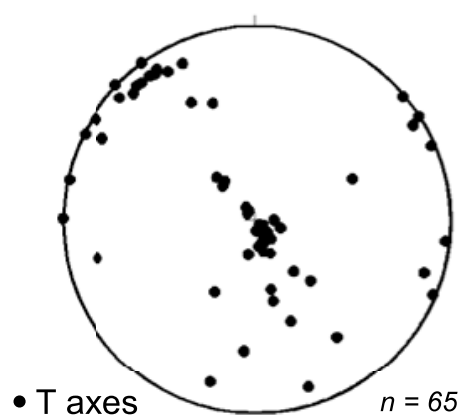

Figure 6. Moment tensors determined from AE events recorded during indentation and located using the Geiger algorithm. (a) Source type (or $T-k$ ) plot of the AE source mechanisms with position of doublecouple (DC), isotropic (ISO), vector dipole (VD), and compensated linear vector dipole (CLVD) sources plotted (see equations (2) and (3)). (b) As in Figure 6a but showing events as uncertainty polygons. (c) Plot showing the proportion of the isotropic (ISO) component of the moment tensor over time. (d) Plot showing the plunge of intermediate $B$ (or null) axes (solid blue circles) and tensile $T$ axes (open red circles) of AE events through time. (e) Cumulative frequency histogram of the ISO component for all AE events. (f) Stereonet showing intermediate $B$ axis orientation for all events. (g) Stereonet showing tensile $T$ axis orientation for all events. Lower hemisphere, equal area projection. 
A

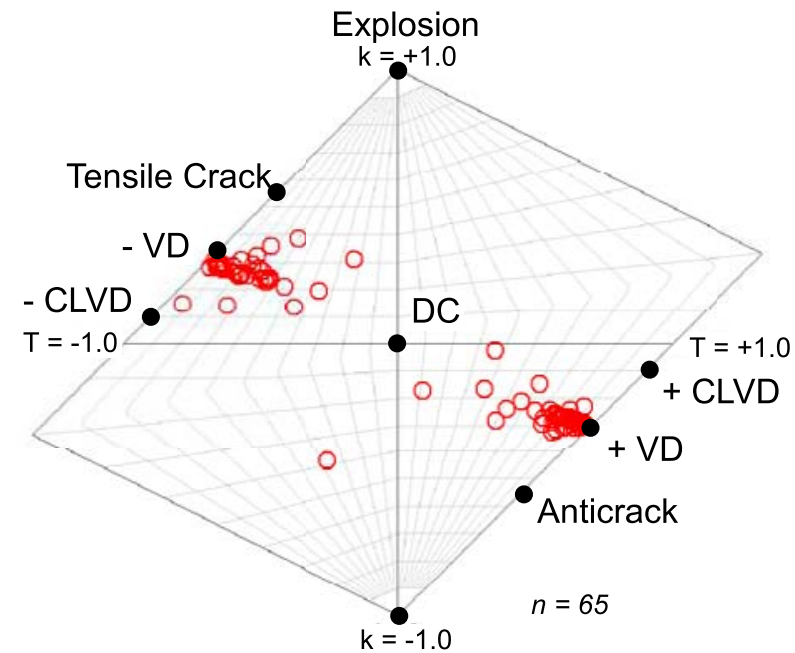

B

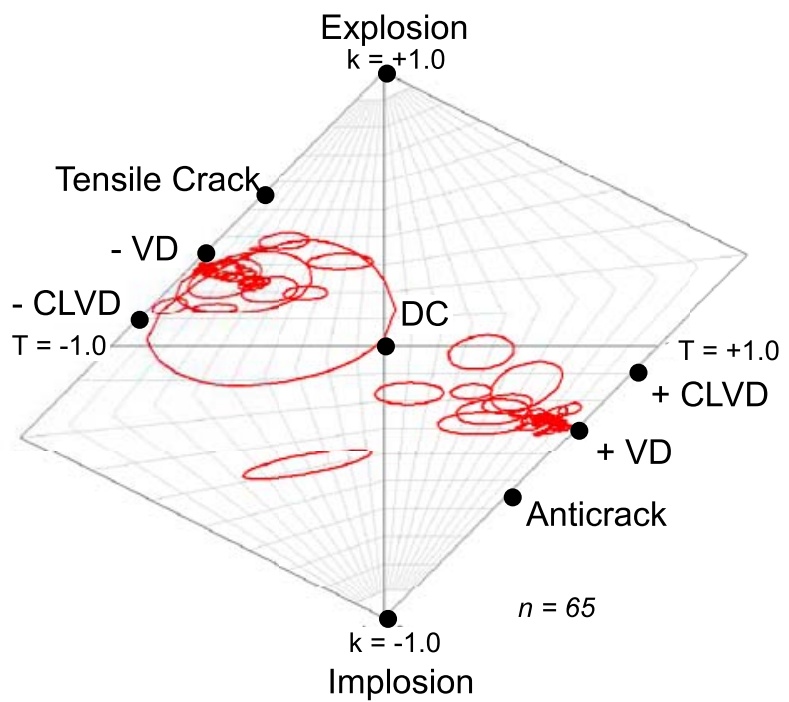

C

Implosion

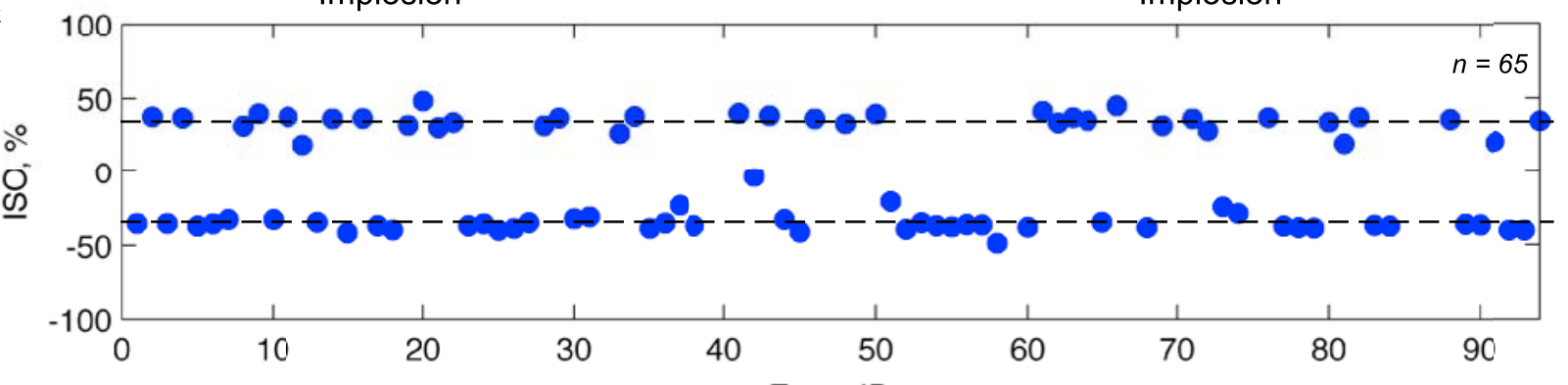

D

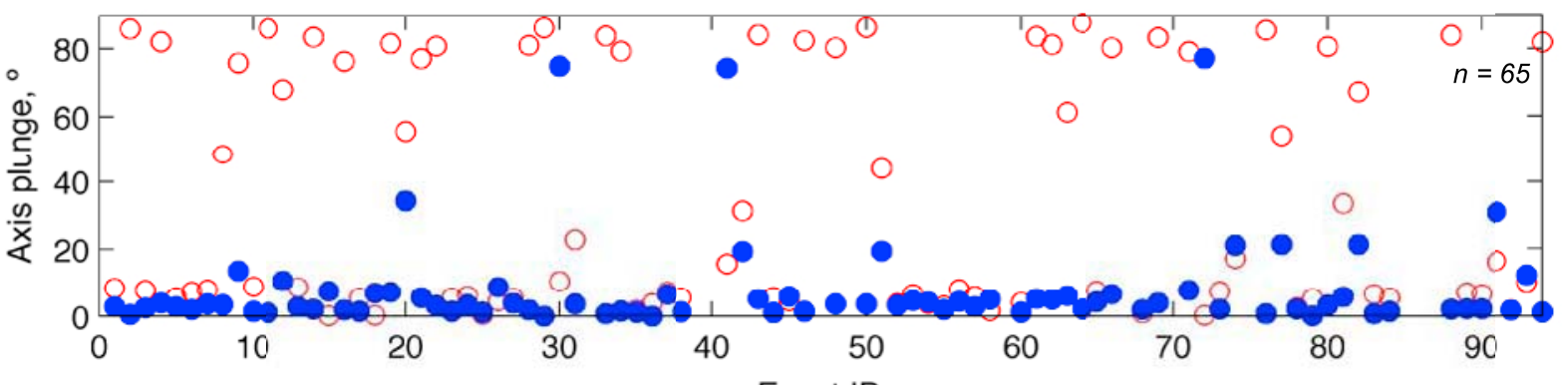

$\mathrm{E}$

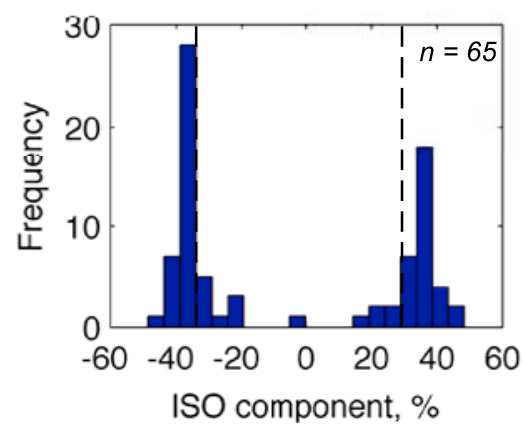

$\mathrm{F}$

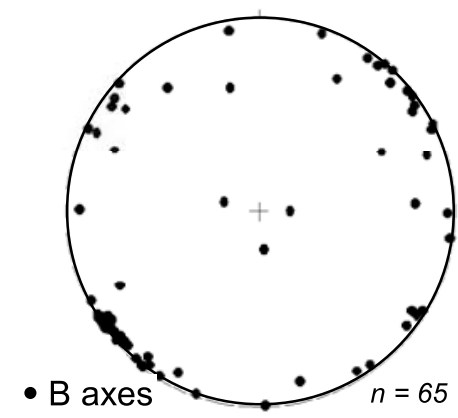

G

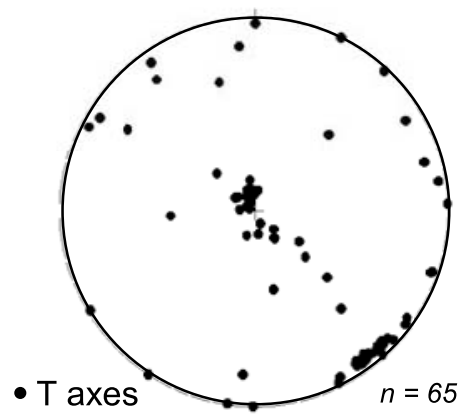

Figure 7. Moment tensors determined from $\mathrm{AE}$ events recorded during indentation and relocated using the master event algorithm. (a) Source type (or $T-k$ ) plot of the AE source mechanisms with position of double-couple (DC), isotropic (ISO), vector dipole (VD), and compensated linear vector dipole (CLVD) sources plotted (see equations (2) and (3)). (b) as in Figure 7a but showing events as uncertainty polygons. (c) Plot showing the proportion of the isotropic (ISO) component of the moment tensor over time. (d) Plot showing the plunge of intermediate $B$ (or null) axes (solid blue circles) and tensile $T$ axes (open red circles) of AE events through time. (e) Cumulative frequency histogram of the ISO component for all AE events. (f) Stereonet showing intermediate $B$ axis orientation for all events. (g) Stereonet showing tensile $T$ axis orientation for all events. Lower hemisphere, equal area projection. 
nent. For the remainder of the $\mathrm{AE}$ events, there is neither clear temporal evolution of the proportion nor the geometry of the $B, T$, or $P$ axes. The master event-relocated events do not show a systematic pattern, having a mixed distribution of $+\mathrm{ve}$ and $-\mathrm{ve}$ ISO events throughout the duration of the experiment (Figures $7 \mathrm{c}$ and $7 \mathrm{~d}$ ).

\subsubsection{Moment Tensors From Elastically Anisotropic Medium Models of Quartz and Calcite}

[25] AE events with prescribed source tensors, i.e., known kinematics (tensile, compressive, shear) for various source orientations, were modeled for single crystal quartz to constrain plausible mechanisms for the observed data and for calcite for comparison (Figure 8). The source mechanisms of these events on the $T-k$ plot deviate from those expected for the same source tensor in an isotropic medium (Figure 8a). For example, modeled tensile events in quartz point toward the vector dipole, while modeled shear events stray from the double-couple position at the center of the plot and show a range of $k$ values (Figure 8a). Overall, the effect of the elastic anisotropy in the quartz lattice on a range of modeled source events is to distribute the $T$ and $k$ values along the diagonal, exactly as observed in the experimental data. Comparison with synthetic moment tensors calculated for the same source tensors in calcite shows a different pattern, where prescribed tensile and compressive source events tend to plot at more extreme $k$ values and deviation of all events from the isotropic case is more extreme than in quartz (Figure 8b).The exact deviation appears to be dependent on the kinematics of the crack (prescribed in the source tensor) with respect to the symmetry and magnitude of the crystallographically controlled elastic anisotropy. This phenomenon can be further visualized through decomposition of these modeled moment tensors into isotropic, double-couple, and compensated linear vector dipole components, and these show that the distinct locations on the $T-k$ plot are reflected in distinct percentages of the different components for quartz and calcite, for the same source tensor orientation (Figures $8 \mathrm{c}$ and $8 \mathrm{~d}$ ). We infer that the observed source mechanisms derived from decomposition of the $\mathrm{AE}$ moment tensors are indeed combinations of shear faulting and tensile/compressive cracking and that the apparent "dipole signal" on the $T-k$ plot is an artefact due to the effects of elastic anisotropy in the quartz lattice on the moment tensor.

\subsection{Analysis of the Cone Crack Tip Process Zone}

[26] EBSD mapping of the cone crack tip zone does not show resolvable $\left(>0.3^{\circ}\right)$ changes in orientation of the quartz lattice across the main fracture trace. The EBSP band contrast map does reveal several discrete overlapping en echelon bands of low EBSP quality that have the same bulk trend as the visible crack (Figure 9a). Each band is approximately 1-3 $\mu \mathrm{m}$ wide, which together form a zone approximately $40 \mu \mathrm{m}$ wide (Figures 9a and 9b). Given the uniformity of pattern quality elsewhere, these bands are interpreted as localized planes of damaged lattice and may mark the trace of the process zone ahead of the propagating crack tip [Vermilye and Scholz, 1998b]. The planes are crystallographically controlled and most likely [01-1-2] planes (Figure 9c). Coalescence of these surfaces would likely result in a microscopically stepped fracture morphology [Norton and Atkinson, 1981].

\section{Discussion}

\subsection{Effects of Anisotropy on the Geometry of Cone Crack Development}

[27] The symmetric, tricuspate morphology of the cone crack surface reflects the crystallographic symmetry of the sample and is similar to those produced by indentation loading of synthetic quartz [Hartley and Wilshaw, 1973]. The very nature of a conical crack in a crystalline material requires fracture along many different crystallographic planes at the lattice scale. Therefore, it is perhaps not surprising that the cone crack has propagated via linkage of segments comprising crystallographically weak planes (Figures $4 \mathrm{~b}$ and 9). The trigonal cuspate morphology of the cone crack reflects the dominance of a weaker symmetric plane, perhaps following directional minima in fracture toughness in quartz. Similar symmetric steps have been observed on quartz fracture surfaces elsewhere [Ball and Payne, 1976; Norton and Atkinson, 1981].

\subsection{Effects of Anisotropy on AE Locations}

[28] The unrealistic scatter of the absolute located AE events can be attributed to the geometry of the array, which, although surrounding the source area with a complete azimuthal coverage, is limited in the vertical coordinate direction by the size of the sample plus the effects of the velocity anisotropy sampled by the pinducer array. The relative "master event" routine clearly located the events much more accurately and is a superior approach in this scenario (Figure 5). The accuracy of the relative approach indicates that the effects of the crystallographic anisotropy are the primary cause of inaccurate location using the absolute approach. In fact, the position of the pinducers along the $\mathrm{m}$ faces meant that alternate lower tier sensors sampled close to the $V_{\mathrm{p}}$ and $V_{\mathrm{s}}$ maxima and minima for events sourced near the center of the sample (Figure 1a), the effects of which are to draw located events deeper within the sample volume than the real location. Undoubtedly, AE location by either of the techniques could have been improved with better focal coverage of the pinducers.

[29] One possibility for AE events located above the sample surface, even using the relative location approach, could be due to the effects of frictional sliding of the ball bearing in the steel core inside indenter tip during loading. Alternatively, it could be the result of preexisting crack damage in the raypaths between $\mathrm{AE}$ source and pinducers, resulting in longer travel times. Such changes in the velocity structure cannot be accounted for in either of the location techniques. The accumulated crack damage is localized at the sample surface and not sufficiently deep to be detected during velocity surveys, which were undertaken from the lower tier pinducer array $(Z=\sim 13 \mathrm{~mm})$. This is supported by the presence of more AE events located above the sample surface later in the experiment, i.e., after more accumulated fracture damage. 
A Quartz

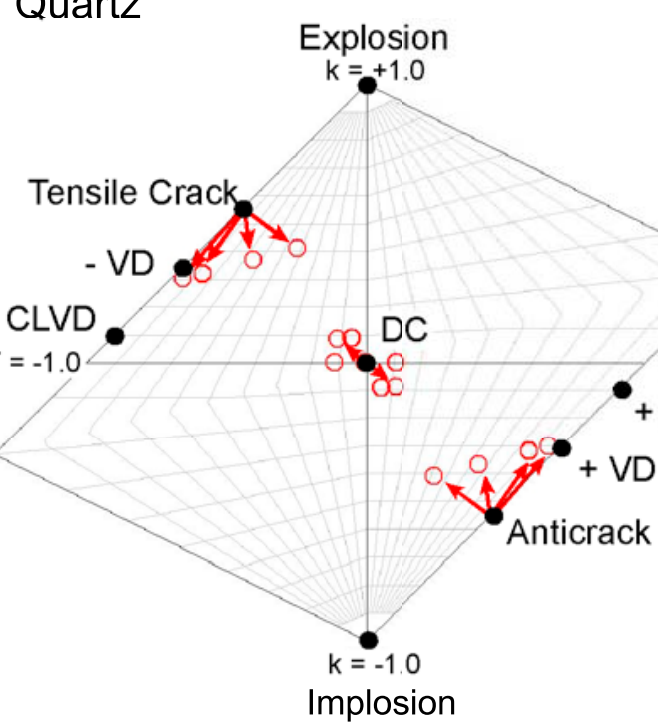

C Quartz

Tensile

Isotropic

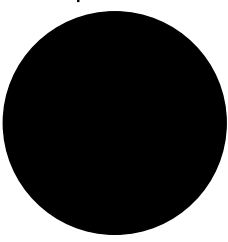

$30.37 \%$

Combined

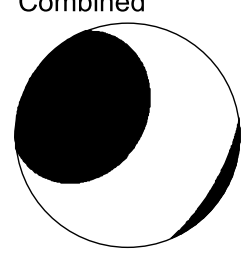

$\mathrm{DC}$

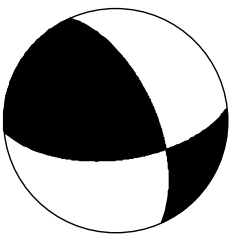

$3.59 \%$

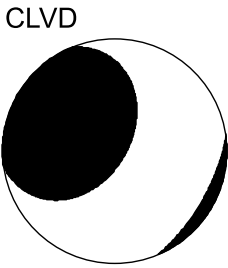

$66.04 \%$
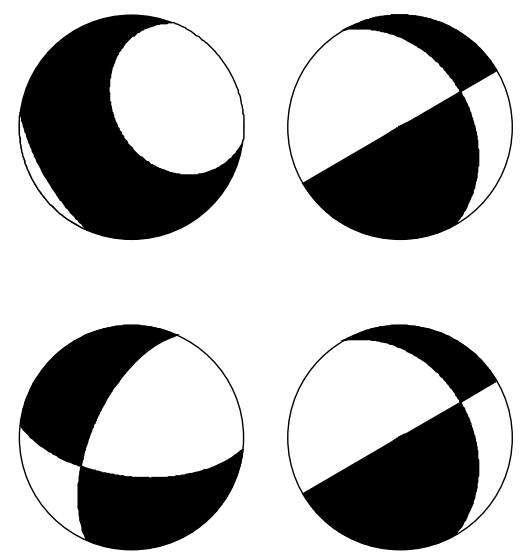

$3.59 \%$

\section{Compressive}

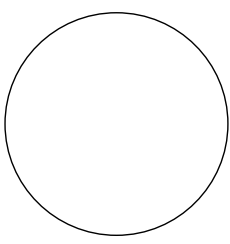

$-30.37 \%$

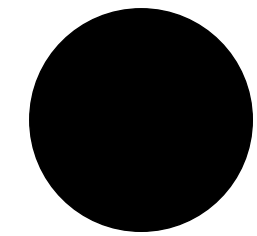

$0.05 \%$

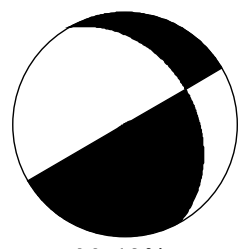

$99.43 \%$

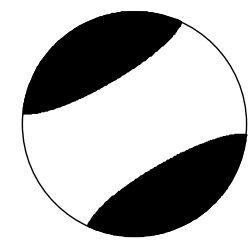

$66.04 \%$

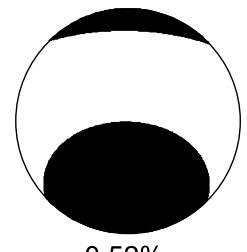

B Calcite

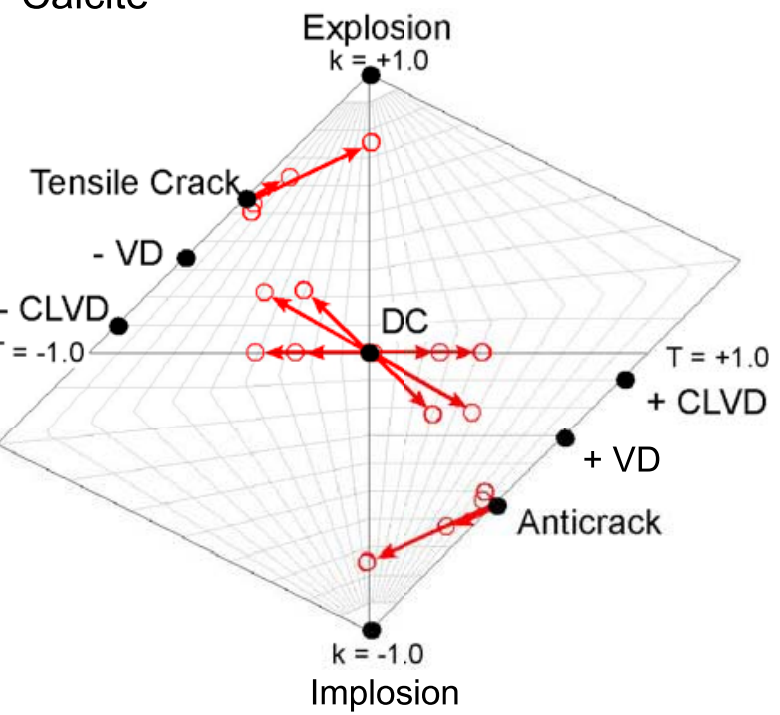

D Calcite

Tensile Compressive Shear Isotropic

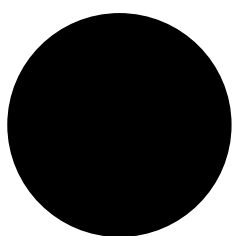

$50.61 \%$

Combined

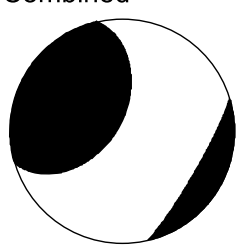

DC

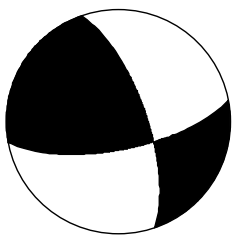

$7.19 \%$

CLVD

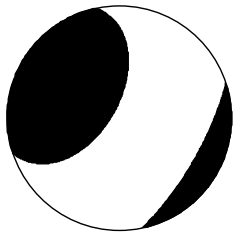

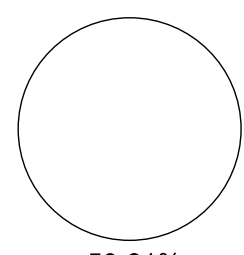

$-50.61 \%$
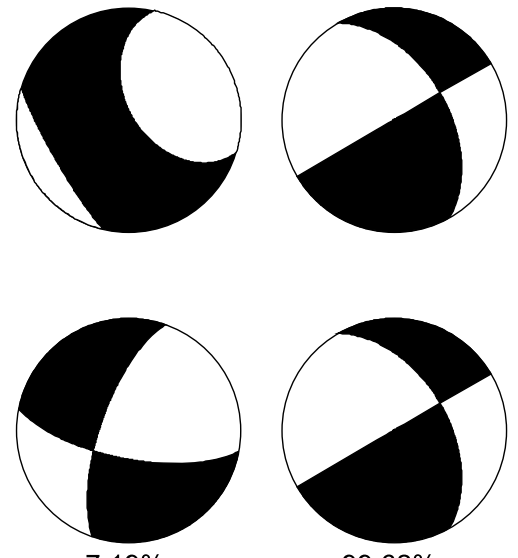

$7.19 \%$

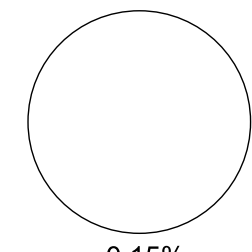

$-0.15 \%$

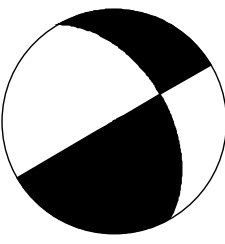

$99.62 \%$

$42.20 \%$

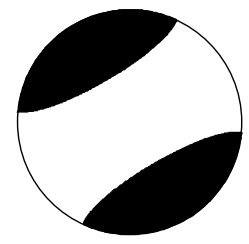

$42.20 \%$

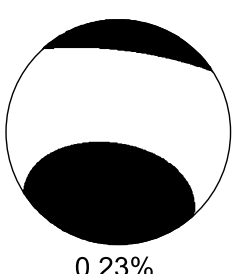

Figure 8 

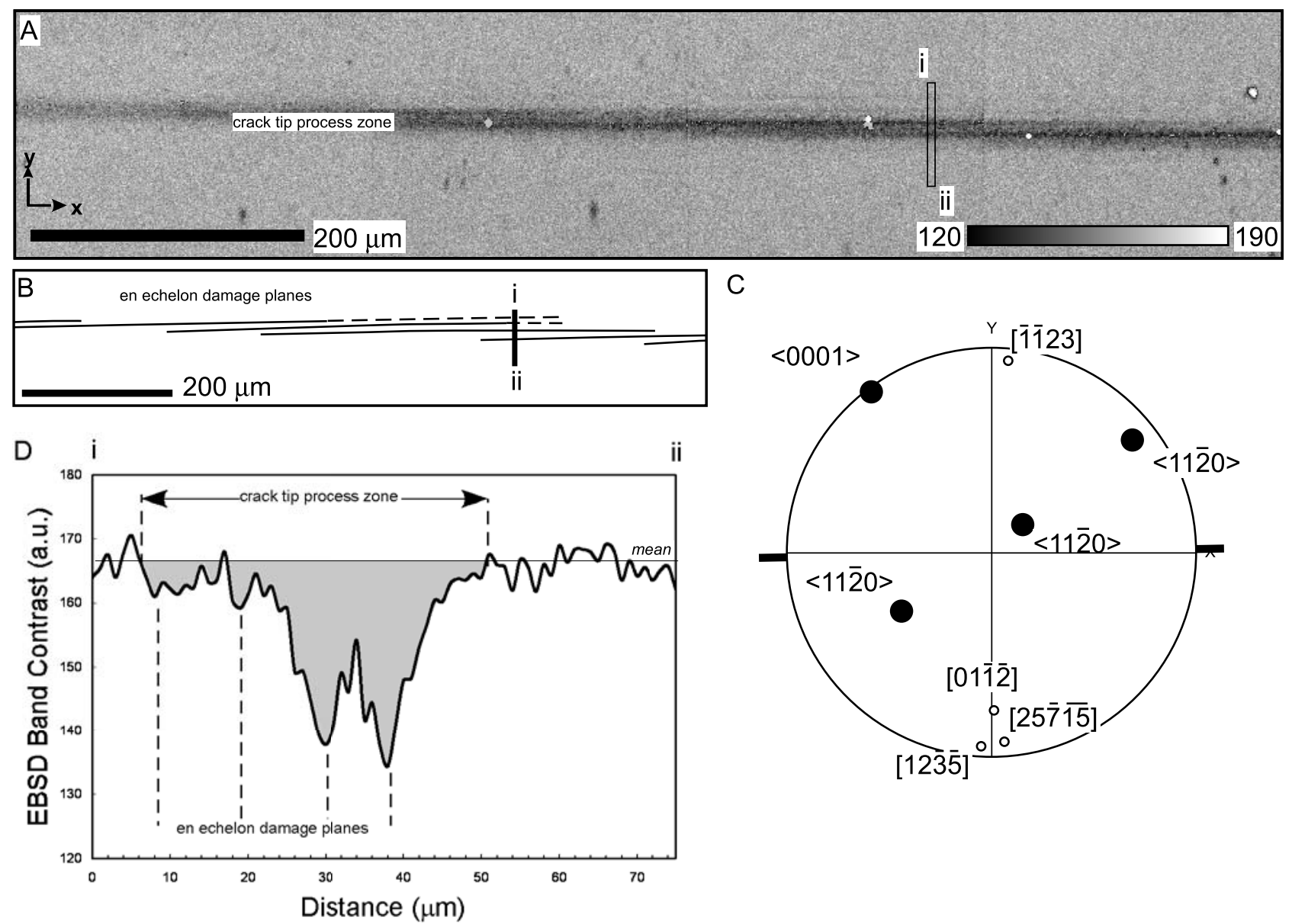

C

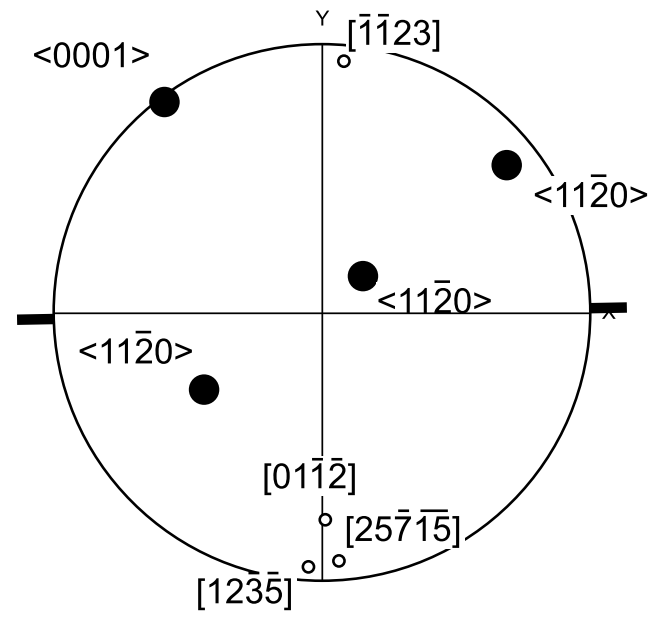

Figure 9. Electron backscatter diffraction (EBSD) analysis of damage developed ahead of the crack tip on a surface cut perpendicular to the crack tip, where there is no visible brittle fracture. (a) Map of electron backscatter pattern (EBSP) band contrast (pattern quality) (area a shown in Figure 4g) reveals a band of weak EBSPs interpreted to be a zone crystallographic damage. Arbitrary units. (b) Schematic diagram of the detailed structure of the damage zone shown in Figure 9a illustrating low-angle, en echelon, and overlapping bands of significantly reduced EBSP quality (dark gray) that relate to damage along weak crystallographic planes. (c) Lower hemisphere pole figure in the $x-y-z$ reference frame of the EBSD map showing $\langle a\rangle$ and $\langle c\rangle$ directions and the position of poles to crystallographic planes that could explain the en echelon bands along which damage is focused. (d) Profiles $i$ and ii shown in Figures $9 \mathrm{a}$ and $9 \mathrm{~b}$ show the reduction in EBSP quality over $\sim 40 \mu \mathrm{m}$ zone with evenly spaced, $\sim 5 \mu \mathrm{m}$ wide troughs that relate to the en echelon bands. Reference level is the mean from the undamaged host.

\subsection{Effects of Relocation Accuracy and Elastic Anisotropy on AE Source Mechanisms}

[30] Our analysis shows that the choice of relocation algorithm and, therefore, AE location accuracy affects the
$\mathrm{AE}$ event moment tensors. This is evident in the higher degree of uncertainty and higher proportion of DC events determined for the Geiger located events. The linear scatter of Geiger located events toward higher DC components on

Figure 8. The effects of crystallographic anisotropy on AE source mechanisms for (a) quartz and (b) calcite. (a) Moment tensors for modeled events with different fracture plane orientations (strike, dip) and kinematics (tensile, compressive, and shear) in quartz. Note that these events, calculated using the anisotropic elastic properties of quartz, plot away from the "expected" locations for the elastically isotropic case. Arrows show the departure of the anisotropic events from the standard isotropic locations (Figure 6). (b) Moment tensors for modeled events with the same geometry and kinematics shown in Figure 8a, but now for calcite. The distinct anisotropic elastic properties of calcite result in different locations on the source type plot, even though the prescribed source tensor has not changed. (c) Moment tensor components for selected modeled tensile, compressive, and shear events for quartz. (d) Modeled tensor components for tensile, compressive, and shear events in calcite. In both Figures $8 \mathrm{c}$ and $8 \mathrm{~d}$, the same prescribed source tensors were used with orientations of $030 / 45^{\circ} \mathrm{S}, 150 / 45^{\circ} \mathrm{S}$, and $150 / 45^{\circ} \mathrm{N}$ and unit slip (either tensile, compressive or shear) over unit area. Moment magnitudes have been normalized by the maximum moment to produce equally sized "beach balls." 
the $T-k$ plot is due to distorted sensor focal sphere coverage from inaccurately located hypocenters (Figures $6 \mathrm{a}$ and $6 \mathrm{~b}$ ). The higher accuracy of master event-relocated events yields increased accuracy in the focal sphere coverage of sensors around the source and, therefore, more realistic moment tensor determination (Figures $7 \mathrm{a}$ and $7 \mathrm{~b}$ ).

[31] The calculated synthetic moment tensors plotted in Figure 8 do not account for the presence of the free surface at the top of the sample. However, we believe the general trend of these synthetic events on the $T-k$ plot is fundamentally controlled by the effect of elastic anisotropy. The comparison with the synthetic moment tensors in calcite using the same source tensors as for the synthetic quartz events shows the strong and distinct control of mineralogical elastic anisotropy on the apparently anomalous source mechanisms. This comparison lends confidence to the idea that the observed effect in the quartz sample is chiefly due to the elastic anisotropy of the quartz lattice. The complexity of the pattern of modification of moment tensors by crystallographic anisotropy highlights the need for further detailed understanding of the effects of anisotropy on interpreting (micro)seismic source mechanisms from the fracture of anisotropic materials.

\subsection{Kinematic Evolution of Cone Cracks in Quartz}

[32] An outward progression of crack initiation subsidiary concentric cracks is consistent with the effects of the increased indenter sample contact area over time. However, the $\mathrm{AE}$ source mechanisms indicate that the kinematic development of a "Hertzian" cone crack in quartz is much more complex than previously envisaged and involves the outward progression of successive quasi-concentric ring cracks with kinematic switching between tensile and compressive modes throughout the deformation. A potential cause of switching between +ve and -ve ISO components could relate to the kinematic evolution of each individual ring crack. Initially, the crack opens in tension (+ve dilatation, +ve ISO component) and propagates with a curved trajectory into a ring shape, controlled by the local orientation of the most tensile principal stress $\left(\sigma_{3}\right)$. With increased loading, a new peripheral crack is initiated and the kinematics of the earlier crack switch to a dominantly anticrack mechanism (indicated by presence of -ve ISO component), and so on. The increasing contact area between indenter and sample means that early formed tensile cracks will later be subjected to compressive stress as the contact area grows outward over the previously formed, mainly tensile surface damage. A view of the initiation orientation of each fracture can be seen using the $B$ axes (neutral directions) from the moment tensors. The subhorizontal plunge of all of the $B$ axes is consistent with the intermediate stress aligned with the free surface of the sample, as expected from the indentation loading geometry (Figure 7f). However, the preferred orientation of the $B$ axis azimuths in just a few different orientations is puzzling. $B$ axis orientations do not show an even azimuthal distribution as expected from the even distribution of randomly nucleated circular ring crack orientations (Figure 4e) nor do they all coincide with low-index crystallographic directions. An alternative explanation for the orientation bias in the crack initiation is that these dominant orientations stem from microscopic heterogeneities at the indenter-quartz interface, possibly exacerbated by minor tapering of the sample that resulted in nonorthogonal loading.

\section{Conclusions}

[33] A simple, well-constrained (uniaxial loading, ambient $P$ and $T$ ) indentation experiment on a single crystal of quartz (vertical $c$ axis) shows that intragranular fracture in quartz is controlled by the anisotropy of the quartz lattice in the following ways:

[34] 1. The resultant cone crack has significant deviation from the isotropic case and has trigonal symmetry that relates to the crystallography of the sample.

[35] 2. The process zone ahead of the crack tip comprises "damage" planes of weak lattice planes.

[36] 3. The strong velocity anisotropy of quartz means that location of $\mathrm{AE}$ events generated during fracture development are more accurately located using a relative "master event" routine rather than an absolute "Geiger" algorithm assuming a single velocity model at this scale.

[37] 4. The correct interpretation of AE source mechanism is highly dependent on the geometry of sensor coverage in a focal sphere around the source, which relies on the accuracy of $\mathrm{AE}$ location, and ultimately the choice of $\mathrm{AE}$ location algorithm.

[38] 5. Calculated source mechanisms for $\mathrm{AE}$ events during deformation show a distribution on a $T-k$ plot, which may wholly be explained as an artefact induced by the effects of strong elastic anisotropy on moment tensors.

[39] Grain-scale microcracks form the building blocks for larger-scale brittle fractures, such as joints and faults. Our data show nonplanar microcracks with geometries controlled by the crystallographic anisotropy of the host grain. Models of fault nucleation and growth, based on patterns of microcracks gathered from quartz under the erroneous assumptions that quartz is "effectively" isotropic and that intragranular cracks are planar, need revision. More data are required for other minerals and more detailed research to define the precise controls on fracture mechanisms at the grain scale and the consequences for rock failure at a larger scale.

[40] Acknowledgments. N. Timms acknowledges a Royal Society of Engineering Anglo-Australian Fellowship and a Curtin Internal Research grant that supported the research. N. Timms also thanks Karen Mair for initial discussion. D. Healy thanks Bruce Julian (USGS) for code to test moment tensor decompositions and The Institute for Geoscience Research (TIGeR) at Curtin for a Research Fellowship. Reviewers Sergei Stanchits and David Mainprice are thanked for their constructive remarks that led to improvement of the manuscript. This is TIGeR publication 212 .

\section{References}

Aki, K., and P. G. Richards (2002), Quantitative Seismology, 2nd ed., 687 pp., W. H. Freeman and Co., San Francisco, Calif.

Anders, M. H., and D. V. Wiltschko (1994), Microfracturing, paleostress and the growth of faults, J. Struct. Geol., 16, 795-815.

Atkinson, B. K. (1982), Subcritical crack propagation in rocks: Theory, experimental results and applications, J. Struct. Geol., 4, 41-56.

Atkinson, B. K., and V. Avdis (1980), Fracture mechanics parameters of some rock-forming minerals determined using an indentation technique, Int. J. Rock Mech. Min. Sci. Geomech. Abstr., 17, 383-386. 
Babuška, V., and M. Cara (1991), Seismic Anisotropy in the Earth, 215 pp., Kluwer Academic, Dordrecht.

Ball, A., and B. W. Payne (1976), The tensile fracture of quartz crystals, J. Mater. Sci., 11, 731-740.

Blackman, D. K., H. R. Wenk, and J. M. Kendall (2002), Seismic anisotropy of the upper mantle 1. Factors that affect mineral texture and effective elastic properties, Geochem. Geophys. Geosyst., 3(9), 8601, doi:10.1029/ 2001GC000248.

Cayzer, N. J., S. Odake, B. Harte, and H. Kagi (2008), Plastic deformation of lower mantle diamonds by inclusion phase transformations, Eur. J. Mineral., 20, 333-339.

Collins, D. S., W. S. Pettitt, and R. P. Young (2002), High-resolution mechanics of a micro-earthquake sequence, Pure Appl. Geophys., 159(1-3), $197-219$

Deichmann, N., and M. Garcia-Fernandez (1992), Rupture Geometry from High-Precision Relative Hypocenter Locations of Microearthquake Clusters, Geophys. J. Int., 110, 501-517.

de Ronde, A. A., D. P. Dobson, P. G. Meredith, and S. A. Boon (2007) Three-dimensional location and waveform analysis of microseismicity in multi-anvil experiments, Geophys. J. Int., 171, 1282-1294.

Dziewonski, A. M., G. Ekström, J. E. Franzen, and J. H. Woodhouse (1987), Centroid-moment tensor solutions for January-March 1986, Phys. Earth Planet. Inter., 45, 1-10.

ESG (2001), HYPERION Ultrasonic Monitoring System, Hardware and Software User's Guide Version 6.0, Engineering Seismology Group Inc., Kingston, Canada.

Ferguson, C. C., G. E. Lloyd, and R. J. Knipe (1987), Fracture mechanics and deformation processes in natural quartz; a combined Vickers indentation, SEM, and TEM study, Can. J. Earth Sci., 24, 544-555.

Hallbauer, D. K., H. Wagner, and N. G. W. Cook (1973), Some observations concerning the microscopic and mechanical behaviour of quartzite specimens in stiff, triaxial compression tests, Int. J. Rock Mech. Min. Sci. Geomech. Abstr., 10, 713-726.

Hartley, N. E. W., and T. R. Wilshaw (1973), Deformation and fracture of synthetic $\alpha$-quartz, J. Mater. Sci., 8, 265-278.

Healy, D., R. R. Jones, and R. E. Holdsworth (2006), Three-dimensional brittle shear fracturing by tensile crack interaction, Nature, 439, 64-67.

Healy, D., S. M. Reddy, N. E. Timms, E. M. Gray, and A. V. Brovarone (2009), Trench-parallel fast axes of seismic anisotropy due to fluid-filled cracks in subducting slabs, Earth Planet. Sci. Lett., 283, 75-86.

Hearmon, R. F. S. (1956), The elastic constants of anisotropic materials II, Advanced Physics, 5.

Hertz, H. (1896), Hertz's Miscellaneous Papers; Chs. 5 and 6., Macmillan, London, UK.

Hess, H. H. (1964), Seismic anisotropy of the uppermost mantle under oceans, Nature, 203, 629-631.

Hudson, J. A., R. G. Pearce, and R. M. Rogers (1989), Source type plot for inversion of the moment tensor, J. Geophys. Res., 94, 765-774.

Jones, G., S. Nippress, A. Rietbrock, and J. Reyes-Montes (2008), Accurate location of synthetic acoustic emissions and location sensitivity to relocation methods, velocity perturbations, and seismic anisotropy, Pure Appl. Geophys., 165, 235-254.

Julian, B. R., A. D. Miller, and G. R. Foulger (1998), Non-double-couple earthquakes. 1. Theory, Rev. Geophys., 36, 525-549.

Kawasaki, I., and T. Tanimoto (1981), Radiation patterns of body waves due to the seismic dislocation occurring in an anisotropic source medium, B. Seismol. Soc. Am., 71, 37-50.

Knopoff, L., and M. J. Randall (1970), The compensated linear-vector dipole: A possible mechanism for deep earthquakes, J. Geophys. Res., 75 .

Kocer, C., and R. E. Collins (1998), Angle of Hertzian cone cracks, J. Am Ceram. Soc., 81, 1736-1742.

Kranz, R. L. (1983), Microcracks in rocks: A review, Tectonophysics, 100, 449-480.

Lawn, B. R. (1998), Indentation of Ceramics with Spheres: A Century after Hertz, J. Am. Ceram. Soc., 81, 1977-1994.

Lehockey, E. M., Y.-P. Lin, and O. E. Lepik (2000), Mapping redidual plastic strain in materials using electron backscatter diffraction, in Electron Backscatter Diffraction in Materials Science, edited by A. J. Schwartz, M. Kumar, and B. L. Adams, pp. 247-264, Kluwer Academic/Plenum

Lloyd, G. E., and J. M. Kendall (2005), Petrofabric-derived seismic properties of a mylonitic quartz simple shear zone; implications for seismic reflection profiling, Geol. Soc. Spec. Pub., 240, 75-94.

Lockner, D. A., J. D. Byerlee, V. Kuksenko, A. Ponomarev, and A. Sidorin (1992), Observations of quasistatic fault growth from acoustic emissions in Fault Mechanics and Transport Properties of Rocks, edited by B. Evans and T.-F. Wong, pp. 3-31, Academic Press, London.
Mainprice, D., and M. Casey (1990), The calculated seismic properties of quartz mylonites with typical fabrics: relationship to kinematics and temperature, Geophys. J. Int., 103, 599-608.

Mainprice, D., and P. G. Silver (1993), Interpretation of SKS-waves using samples from the subcontinental lithosphere, Phys. Earth Planet. Inter. $78,257-280$.

McEwen, T. J. (1981), Brittle deformation in pitted pebble conglomerates, J. Struct. Geol., 3, 25-37.

Miller, A. D., G. R. Foulger, and B. R. Julian (1998), Non-double-couple earthquakes: 2. Observations, Rev. Geophys., 36, 551-568.

Mitchell, T. M., and D. R. Faulkner (2009), The nature and origin of off-fault damage surrounding strike-slip fault zones with a wide range of displacements: A field study from the Atacama fault system, northern Chile, J. Struct. Geol., 31, 802-816.

Moore, D. E., and D. A. Lockner (1995), The role of microcracking in shear-fracture propagation in granite, J. Struct. Geol., 17, 95-114.

Nemchin, A., N. E. Timms, R. Pidgeon, T. Geisler, S. M. Reddy, and C. Meyer (2009), Timing of crystallization of the lunar magma ocean constrained by the oldest zircon, Nat. Geosci., 2, 133-136.

Norton, M. G., and B. K. Atkinson (1981), Stress-dependent morphological features on fracture surfaces of quartz and glass, Tectonophysics, 77, 283-295.

Pavlis, G. L. (1986), Appraising earthquake hypocenter location errors: A complete, practical approach for single-event locations, B. Seismol. Soc. Am., 76, 1699-1717.

Pettitt, W. S., and M. S. King (2004), Acoustic emission and velocities associated with the formation of sets of parallel fractures in sandstones, Int. J. Rock Mech. Min., 41, 151-156.

Phillips, W. S., L. S. House, and M. C. Fehler (1997), Detailed joint structure in a geothermal reservoir from studies of induced microearthquake clusters, J. Geophys. Res., 102, 11,745-11,763.

Prior, D. J., et al. (1999), The application of electron backscatter diffraction and orientation contrast imaging in the SEM to textural problems in rocks, Am. Mineral., 84, 1741-1759.

Prior, D. J., E. Mariani, and J. Wheeler (2009), EBSD in the Earth Sciences: applications, common practice and challenges, in Electron Backscatter Diffraction in Materials Science, edited by A. J. Schwartz et al., pp. 345-357, Springer.

Reches, Z. E., and D. A. Lockner (1994), Nucleation and growth of faults in brittle rocks, J. Geophys. Res., 99, 18,159-18,173.

Reyes-Montes, J. M., A. Rietbrock, D. S. Collins, and R. P. Young (2005), Relative location of excavation induced microseismicity at the Underground Research Laboratory (AECL, Canada) using surveyed reference events, Geophys. Res. Lett., 32, L05308, doi:10.1029/2004GL021733.

Rietbrock, A., C. Tiberi, F. Scherbaum, and H. Lyon-Caen (1996), Seismic slip on a low angle normal fault in the gulf of corinth: Evidence from high-resolution cluster analysis of microearthquakes, Geophys. Res. Lett. 23, 1817-1820

Rössler, D., G. Rümpker, and F. Krüger (2004), Ambiguous moment tensors and radiation patterns in anisotropic media with applications to the modeling of earthquake mechanisms in W-Bohemia, Stud. Geophys. Geod., 48, 233-250.

Scholz, C. H. (1968), Experimental study of fracturing process in brittle rock, J. Geophys. Res., 73, 1447-1454.

Swain, M. V., J. S. Williams, B. R. Lawn, and J. J. H. Beek (1973), A comparative study of the fracture of various silica modifications using the Hertzian test, J. Mater. Sci., 8, 1153-1164.

Tapponnier, P., and W. F. Brace (1976), Development of stress-induced microcracks in Westerly Granite, Int. J. Rock Mech. Min. Sci. Geomech. Abstr., 13, 103-112.

Tatham, D. J., G. E. Lloyd, R. W. H. Butler, and M. Casey (2008), Amphibole and lower crustal seismic properties, Earth Planet. Sci. Lett., 267, $118-128$.

Thompson, B., R. Young, and D. Lockner (2006), Fracture in westerly granite under AE feedback and constant strain rate loading: Nucleation, quasi-static propagation, and the transition to unstable fracture propagation, Pure Appl. Geophys., 163, 995-1019.

Tucker, A. T., A. J. Wilkinson, M. B. Henderson, H. S. Ubhi, and J. W. Martin (2000), Measurement of fatigue crack plastic zones in fine grained materials using electron backscattered diffraction, Mater. Sci. Tech., 16, 457-462.

Vavryčuk, V. (2002), Non-double-couple earthquakes of 1997 January in West Bohemia, Czech Republic: Evidence of tensile faulting, Geophys. J. Int., 149, 364-373.

Vavryčuk, V. (2004), Inversion for anisotropy from non-double-couple components of moment tensors, J. Geophys. Res., 109, B07306, doi:10.1029/2003JB002926.

Vavryčuk, V. (2005), Focal mechanisms in anisotropic media, Geophys $J$ Int., 161, 334-346. 
Vermilye, J. M., and C. H. Scholz (1998a), The process zone: A microstructural view of fault growth, J. Geophys. Res., 103.

Vermilye, J. M., and C. H. Scholz (1998b), The process zone: A microstructural view of fault growth, J. Geophys. Res., 103, 12,223-12,237.

Wilkinson, A. J. (2000), Measuring strains using electron backscatter diffraction, in Electron Backsactter Diffraction in Materials Science, edited by A. J. Schwartz, M. Kumar, and B. L. Adams, pp. 231-246, Kluwer Academic/Plenum.

Wilson, J. E., J. S. Chester, and F. M. Chester (2003), Microfracture analysis of fault growth and wear processes, Punchbowl Fault, San Andreas system, California, J. Struct. Geol., 25(11), 1855-1873.

Wong, T. F. (1982), Micromechanics of faulting in westerly granite, Int. J. Rock Mech. Min., 19, 49-64.

Yang, Z.-X., Y.-T. Chen, and H.-Z. Zhang (2002), Relocation and seismogenic structure of the 1998 Zhangbei-Shangyi earthquake sequence, Acto Seismol. Sin., 15(4), 383-394.
Yingzhi, L., and D. A. Hills (1991), The Hertzian cone crack, J. Appl. Mech., 58, 120-127.

D. S. Collins, Engineering Seismology Group, 20 Hyperion Court, Kingston, ON K7K 7G3, Canada.

D. Healy, Department of Geology and Petroleum Geology, School of Geosciences, University of Aberdeen, King's College, Aberdeen, Aberdeen City, AB24 3UE, UK.

D. J. Prior, Department of Earth and Ocean Sciences, University of Liverpool, 4 Brownlow St., Liverpool, Merseyside L69 3GP, UK

J. M. Reyes-Montes, Applied Seismology Consultants, 5 Claremont Buildings, Claremont Bank, Shrewsbury, Shropshire SY1 1RJ, UK.

N. E. Timms, Department of Applied Geology, Western Australia Geothermal Centre of Excellence, Curtin University of Technology, GPO Box U1987, Perth, WA 6845, Australia. (n.timms@curtin.edu.au)

R. P. Young, Department of Geology, University of Toronto, Lassonde Institute, 170 College St., Toronto, ON M5S 3E3, Canada. 